\title{
Electrospinning of Polymer Nanofibers for Tissue Regeneration
}

Tao Jiang ${ }^{\text {a,b,c } * \text {, Erica J. Carbone }}{ }^{\text {a,b,c }}$, Kevin W.-H. Lo ${ }^{\text {a,b,c,f }}$, and Cato T. Laurencin ${ }^{\text {b,c,d,e,f }}$ *

${ }^{a}$ Department of Medicine, Division of Endocrinology, University of Connecticut Health Center, Farmington, Connecticut 06030, USA

${ }^{\mathrm{b}}$ Institute for Regenerative Engineering, University of Connecticut Health Center, Farmington, Connecticut 06030, USA

${ }^{c}$ Raymond and Beverly Sackler Center for Biological, Physical and Engineering Sciences, University of Connecticut Health Center, Connecticut 06030, USA

${ }^{\mathrm{d}}$ Department of Orthopaedic Surgery, University of Connecticut Health Center, Farmington, Connecticut 06030, USA

${ }^{\mathrm{e}}$ Department of Chemical, Materials and Biomolecular Engineering, University of Connecticut, Storrs, Connecticut 06269, USA

${ }^{\mathrm{f}}$ Department of Biomedical Engineering, University of Connecticut, Storrs, Connecticut 06269, USA

*Corresponding Authors: jiang@uchc.edu Ph: +1 860-679-7161 Fax: +1 860-679-1553

Laurencin@uchc.edu Ph: +1 860-679-2594 Fax: +1 860-679-1255 Email: 


\begin{abstract}
Repair and regeneration of human tissues and organs using biomaterials, cells, and/or growth factors is a great challenge for tissue engineers and surgeons. The convergence of advanced materials science, nanotechnology, stem cell science, and developmental biology, which we define as Regenerative Engineering, represents the next multidisciplinary paradigm to engineer complex tissues. One of the grand challenges in this field is to mimic closely the hierarchical architecture and properties of the extracellular matrices (ECM) of the native tissues. A bio-inspired approach to creating biomaterials with nanoscale topographical features, microand macroscale gradient structures, and biological domains to interact with target growth factors and cells is key to overcoming this challenge for successful tissue regeneration. Furthermore, the healing and repair of diseased musculoskeletal tissues rely on many signaling pathways, involving numerous growth factors and their receptors. Thus, pharmacological manipulation of the signaling pathways with bioactive molecules is an important component of tissue regeneration. This review summarizes current strategies to develop advanced nanofibrous polymer-based scaffolds via electrospinning, their applications in regenerating human musculoskeletal tissues, and the use of polymer nanofibers to deliver growth factors or small molecules for regenerative medicine.
\end{abstract}

Keywords: electrospinning, nanofiber, scaffold, musculoskeletal regenerative engineering, growth factor, small molecule 


\section{Table of Contents}

1. Introduction

2. Electrospinning Polymers

2.1. Polymer Nanofiber Synthesis

2.2. Characterization of Nanofibers and Nanofibrous Scaffolds

3. Advanced Nanofibrous Scaffolds

3.1. Scaffolds Comprised of Aligned Nanofibers

3.2. Scaffolds Comprised of Multiphasic Micro- or Nanofibers

3.3. Nanofibrous Scaffolds with Gradients

3.4. Nanofibrous Scaffolds with Superior Mechanical Properties

3.5. Nanofibrous Scaffolds with Large Pores

4. Applications of Nanofibers in Musculoskeletal Tissue Regeneration

4.1. Nanofibers for the Regeneration of Bone

4.2 Nanofibers for the Regeneration of Soft Musculoskeletal Tissues

5. Nanofiber-Based Delivery of Signaling Molecules for Musculoskeletal Tissue Regeneration

\subsection{Growth Factor Delivery}

5.2. Small Molecule Delivery

6. Challenges in Electrospinning and Nanofibrous Scaffolds for Tissue Regeneration

7. Conclusions and Future Outlook

Acknowledgements

References 


\section{Introduction}

Musculoskeletal tissue related diseases affect millions of people in the U.S. and worldwide. The repair or regeneration of damaged or diseased musculoskeletal tissues is a major clinical problem, and has been one of the most challenging tasks for orthopaedic surgeons. Each year, an estimated 1.5 million bone grafting operations, 650,000 reparative knee procedures, 100,000 anterior cruciate ligament (ACL) reconstructions, and 400,000 shoulder surgeries due to a torn rotator cuff are carried out in the U.S. [1-4]. In these procedures, autografts are considered the gold standards for repair. For example, bone taken from the iliac crest and bone-patella tendon-bone grafts are commonly utilized for bone and ACL repair, respectively. Furthermore, a variety of allografts such as allogenic bone, osteochondral, ligament, and tendon grafts have led to superior clinical outcomes [5]. Although autografts and allografts have been overall successful in repairing musculoskeletal tissues, they suffer from various disadvantages such as limited autograft availability and risk of disease transmission associated with allografts $[5,6]$.

To overcome these problems, tissue engineering, in combination with advanced materials science and stem cell science, has evolved since the early 1990s as a popular research frontier and potential therapy to repair individual tissues and organs [7]. Tissue engineering aims to enhance the repair of living tissues using biomaterials, cells, and growth factors alone, or in combination [5]. Biomaterials, fabricated to mimic the structure and function of tissue-specific extracellular matrices (ECM), play multiple significant roles in cell and tissue ingrowth [8]. Progenitor cells and stem cells, which are capable of differentiating into a multitude of phenotypes, are critical in many cases to compensate for a deficiency of normally functional cell populations [9]. Growth factors, typically functioning as signaling molecules by binding to specific transmembrane receptors on target cells, direct and regulate numerous cellular processes 
[10]. In recent years, the importance of convergent research integrating tissue engineering, advanced materials, and stem cells with the seemingly disparate disciplines of physical sciences and developmental biology has been recognized, and a new research direction has been proposed and termed as "regenerative engineering" [11]. While tissue engineering focuses on the ability to repair a specific tissue, regenerative engineering aims to regenerate or reconstruct complex tissues and biological systems, such as the whole human limb. Advanced materials science, nanotechnology, stem cell science, and developmental biology are important fields within this new multidisciplinary paradigm to engineer complex tissues. A bio-inspired approach to creating biomaterials with micro- and nanoscale topographical features, macroscale gradient structures, and biological domains to interact with target growth factors and cells is key to successful tissue regeneration. This bio-inspired approach emphasizes fabrication of materials that mimic the unique structures and properties of natural tissues. Furthermore, neo-tissue development and healing of injured musculoskeletal tissues involve many signaling pathways with the participation of a large number of growth factors and signaling molecules. Thus, pharmacological manipulation of these signaling pathways using small molecules is another important component of regenerative engineering [12].

The application of nanoscale materials is crucial in various approaches to regenerating musculoskeletal tissues for several reasons. First, natural musculoskeletal tissues are composed of finely organized ECM in the nanoscale. For example, natural bone is a nanocomposite material composed mainly of hydroxyapatite nanocrystallites in an organic collagen-rich matrix [13]. The individual, helical collagen chains are $10 \mathrm{~nm}$ in length and self-assemble into organized collagen fibers, measuring approximately $500 \mathrm{~nm}$ in length. Hydroxyapatite, the mineralized inorganic component of bone, exists as plate-like nanocrystals, measuring 20-80nm in length. 
The triple helical structure of collagen gives bone a structural framework with high tensile strength and flexibility, while the nanocrystalline hydroxyapatite provides rigidity and high compressive strength [14]. Second, nanotopographical features, when interacting with cells, have been proven to control and regulate cellular processes as important signaling modalities $[15,16]$. Nanotopography and local environment influence trends in cell behavior by providing chemical and physical stimuli to promote cell adhesion, proliferation, morphogenesis, and motility [17]. The provided stimuli include chemical cues and adsorbed protein motifs, as well as the geometry, dimensions, and aspect-ratios of the nanotopographical features $[17,18]$. ECM materials can be made functional for different musculoskeletal cell types by modifying the stimuli characteristics in order to facilitate cell-matrix interactions at the molecular level.

Nanoscale materials can be fabricated into different forms such as nanoparticles, nanofibers, nanospheres, nanotubes, nanogels, nanocapsules, and surfaces with nanotopographical features. These nanostructures can be prepared using a variety of biofabrication methods such as electrospinning, electrospraying, spray drying, phase separation, molecule self-assembly, chemical vapor deposition, and nano-imprinting. Among these nanostructures, nanofibers fabricated from electrospinning are one of the most widely investigated platforms for tissue regeneration [19]. They are characterized by ultra-thin continuous fibers, high surface-to-volume ratio, high porosity, and adjustable pore size distribution. The highly interconnected porous structure of nanofibrous scaffolds provides an appropriate substrate for cell attachment and nutrient transport [20]. In addition, the ECMmimicking nanofibrous structures have been shown to stimulate in vivo-like organization and morphogenesis of cells in culture [21]. 
This article first provides a concise review of nanofiber synthesis by electrospinning, and focuses particularly on the development of various advanced functional nanofibrous scaffolds. Furthermore, this article provides a comprehensive review on the application of these nanofibrous scaffolds in regenerating various musculoskeletal tissues and as delivery vehicles for growth factors and small molecules for musculoskeletal regenerative engineering.

\section{Electrospinning Polymers}

\subsection{Polymer Nanofiber Synthesis via Electrospinning}

Electrospinning is a fiber-forming process aided by the application of electrostatic forces to control the production of fibers. It is closely related to electrospraying, another wellestablished method of liquid atomization via electrostatic forces to form droplets. Both electrospinning and electrospraying replace the conventional mechanical forces to form the jet and reduce the size of the fibers or droplets; thus, these processes are also known as electrohydrodynamic jetting [22, 23]. Electrospinning first appeared in the literature more than a century ago. In 1902, Cooley [24] and Morton [25] separately patented methods and apparatuses for electrically dispersing fluids, a concept later known as electrospinning. However, it was not until the 1990s that electrospun polymer nanofibers became a topic of great research interest $[26$, 27]. Electrospinning is an attractive technique to synthesize nanofibers from various biodegradable polymers due to the simplicity of the technique, ability to effectively control the process, and potential for production scale-up. Fig. 1A illustrates the general set-up of an electrospinning apparatus used to create polymeric nanofibers. The apparatus consists of a high voltage power supply, a syringe and a syringe pump, a needle connected to the syringe, and a metal collector [23]. High electrical potential is applied between the needle and the grounded 
metal collector. Initially, the polymer solution remains at the tip of the needle due to surface tension. As the electrical potential intensifies, the hemispherical surface of the polymer solution at the needle tip elongates to form a conical shape known as the Taylor cone $[28,29]$. A further increase of the electrical field towards a threshold value causes the formation of a polymer jet as the repulsive electrostatic force overcomes the surface tension. At this point, a polymer jet is ejected from the tip of the Taylor cone and travels rapidly to the metal collector. Before reaching the collector, the jet undergoes a series of electrically driven bending instabilities and gradually thins in air due to elongation and solvent evaporation. The charged jet is eventually collected on a stationary collector (Fig. 1B) and becomes randomly-oriented nanofibers in the form of a nonwoven web (Fig. 1C) [23]. Aligned nanofibers can be fabricated by using either a stationary collector with small changes to the collector or different dynamic collectors [30]. In one configuration as shown in Fig. 1D, a rotating drum collector is used at a very high speed to obtain aligned nanofibers (Fig. 1E).

\section{[Insert Figure 1 here]}

A number of processing parameters can be manipulated to finely tune the diameter and morphology of the nanofibers [30]. First, the properties of the polymer solutions play important roles in determining the electrospinning and electrospraying products. A polymer solution with appropriate viscosity, surface tension, and conductivity is essential to fabricate nanofibers without beads or beads-on-a-string appearance. Whether the polymer jet eventually forms a smooth fiber or is dispersed into droplets depends on the polymer's molecular weight and chain entanglement, as well as the solvent used in the process. If the product of the intrinsic viscosity of the polymer $[\eta]$ and polymer concentration $c$, known as the Berry's number $(B e=[\eta] c)$, is greater than a threshold value, small fibers will be produced and the process is termed 
electrospinning; otherwise, the polymer jet will be disintegrated into droplets and the process is called electrospraying [31]. Specifically in electrospinning, an increase in viscosity leads to an increase in nanofiber diameter, while an increase in the surface tension or conductivity of the polymer solution results in a decrease in nanofiber diameter. Second, the electrical potential that provides a suitable level of charge to the polymer solution is also critical to the electrospinning process. A minimum voltage is required for the polymer solution to be ejected from the tip of the Taylor cone. A further increase in voltage decreases the diameter of the nanofibers; however, a high electrical potential is not desired as it may lead to bead formation or defects in the nanofibers [32]. Other processing parameters that affect the diameter, morphology, and orientation of the formed nanofibers include polymer solution feed rate, the inner diameter of the syringe needle, the distance between spinneret and collector, ambient parameters such as temperature and humidity, and the motion of the grounded collector [30].

A number of polymers have been electrospun into nanofibers for tissue engineering applications. Laurencin and co-workers demonstrated that an electrospun nanofibrous structure could serve as a novel scaffold to engineer tissues [33]. This pioneering work has been recently featured as one of the top 25 papers published by the Journal of Biomedical Materials Research over the past 50 years. Laurencin et al. have since investigated a number of electrospun biodegradable nanofibrous scaffolds using polyphosphazenes, poly(lactide-co-glycolide) (PLGA), and poly (E-caprolactone) (PCL) for wound healing [34], drug delivery [35], and regenerating soft [36-42] and hard tissues [43]. Furthermore, polyphosphazenenanohydroxyapatite composite [44] and polyphosphazene-PLGA blend [45] nanofiber scaffolds, as well as composite scaffolds comprised of poly(L-lactic acid) (PLLA) nanofibers and sintered microspheres [46], have been investigated for bone tissue engineering applications. Many 
research groups have also investigated the electrospinning of a wide range of both natural and synthetic polymers for biomedical engineering applications [20, 47]. Some of the well-studied polymers include chitosan [48-51], gelatin [52, 53], PCL [54, 55], poly(lactic acid) (PLA) [56, 57], poly(1-lactide-co-e-caprolactone) (P(LLA-CL)) [58, 59], polyurethane [60, 61], and their blends [62-66].

\subsection{Characterization of Nanofibers and Nanofibrous Scaffolds}

Electrospun nanofibrous scaffolds consist of ultrathin polymer fibers entangled and packed into 3D constructs. Nanofiber diameter and orientation, controlled by the electrospinning process, play a key role in the microscopic and macroscopic properties of the nanofibrous scaffolds. These properties include pore size and porosity, as well as mechanical and biological characteristics.

Nanofiber diameter and orientation are most commonly measured directly by scanning electron microscopy (SEM) with the aid of image processing software. Typically, a large number of individual nanofibers from different sections of the sample are analyzed using different image analysis software such as Image $\mathrm{J}$, Scion Image, and others [60, 67-70]. Nanofiber orientation can also be analyzed using these digital-image processing tools. A reference line is drawn along the central orientation and the angular deviations of the oriented nanofibers can be determined. The distribution of fiber orientations, ranging from $-90^{\circ}$ to $90^{\circ}$ where $0^{\circ}$ is the direction parallel to the reference line, characterizes the degree of alignment of the nanofibers $[60,69]$.

Pore size, pore size distribution, and porosity can be measured by the experimental methods of mercury intrusion porosimetry, liquid extrusion porosimetry, and capillary flow 
porosimetry. Mercury porosimetry is based on the capillary law governing liquid penetration into small pores, which is expressed by the Washburn equation:

$$
D=\left(\frac{1}{P}\right) 4 \gamma \cos \varphi
$$

where $\mathrm{D}$ is pore diameter, $\mathrm{P}$ is the applied pressure, $\gamma$ is the surface tension, and $\varphi$ is the contact angle. The volume of mercury (V) penetrating the pores is measured directly as a function of applied pressure. This $\mathrm{P}-\mathrm{V}$ information serves as a unique characterization of pore structure. Liquid extrusion porosimetry and capillary flow porosimetry follow the same rule; however, they use a non-mercury wetting liquid and the liquid is extruded from pores by a non-reacting gas. The differential pressure applied to extrude the liquid and the total volume of the extruded liquid corresponds to the pore size and total pore volume, respectively. Mercury intrusion porosimetry is commonly used on rigid porous scaffolds [71, 72], and it has also been used on nanofibrous scaffolds $[73,74]$. However, mercury intrusion requires very high pressure, which may distort the nanofibrous scaffolds or even lead to sample collapse. Furthermore, the high pressure may reduce pore diameter of the nanofibrous scaffolds $[75,76]$. In contrast, liquid extrusion porosimetry and capillary flow porosimetry require approximately $5 \%$ of the pressure needed for mercury intrusion and produce good resolution of peaks; therefore, they have been widely used as the more appropriate methods to characterize the porous structure of nanofibrous scaffolds [76-79]. In addition to these methods, the porosity of nanofibrous scaffolds can be determined by simple gravimetry following the equations below:

App re nt density = Mass of nanofibrous scaffoldScaffold thickness Xscaffold area 
It has been shown that the porosity determined by gravimetry is in agreement with the data from a liquid intrusion method [80], making gravimetry a useful alternative to measure the porosity of nanofibrous scaffolds.

\section{Advanced nanofibrous scaffolds}

Fabrication of scaffolds from nanofibers provides a valuable means to mimic the natural nanoscale ECM of musculoskeletal tissues and provide several key features of the ECM that regulate cell behaviors. As a robust and versatile technique, electrospinning has been applied to produce nanofibers from numerous polymer-based systems, offering opportunities to reconstruct different microenvironments that cells face in vivo. Traditionally, a highly porous, non-woven fibrous mesh with randomly-oriented nanofibers is obtained by collecting the electrospun fibers on a stationary target. This type of nanofiber mesh has been widely researched in tissue engineering applications due to the high surface area and greater than $90 \%$ porosity. The work has been reviewed in great detail elsewhere [20, 81, 82]. Recently, with the improved understanding of material structure-property-function relationships, emphasis has been placed on developing micro- or nano-structures that closely resemble the microenvironments of the native tissues in the body [83]. Specifically, the development of biomimetic materials mimicking the composition, structure, morphology, and bioactivity of natural tissues represents the future of biomaterials research and development $[84,85]$. In this regard, the development of advanced nanofibrous scaffolds for regenerative engineering has attracted significant research interest and has demonstrated superiority over traditional nanofibrous mesh. 


\subsection{Scaffolds comprised of aligned nanofibers}

Many types of musculoskeletal tissues, such as ligament and tendon, are made of collagen fibers with unique anisotropic structures. Therefore, scaffolds with highly ordered nanofibers are advantageous to guide and direct cell proliferation and migration to regenerate these tissues. A number of electrospinning techniques have been successful in producing aligned nanofibrous scaffolds. The most commonly used method involves the use of dynamic rotating collectors. Using a rotating drum collector, researchers have been able to obtain aligned nanofibers from different polymers. It has also been shown that a minimum rotation speed of the mandrel is required for producing aligned nanofibers, and this speed varies among polymers [86, 87]. Other types of rotating collectors, such as a wired drum collector or a rotating collector with sharp edge, have also been successfully used [88, 89]. Another approach to fabricating aligned nanofibers is to control the electrospinning jet path by manipulating the external electric field. Using a collector comprised of either two separate conductive substrates or a ring collector with a point electrode, Xia and colleagues were able to produce either uniaxially aligned or radially aligned nanofibers [90, 91] (Fig. 2A, 2B). Well-aligned nanofibers can also be obtained by introducing an external magnetic field. Yang et al. fabricated arrays of aligned poly(vinyl alcohol) nanofibers by magnetizing the polymer solution with a small amount of magnetic nanoparticles and adding two magnets to the conventional electrospinning setup [92].

More complex, three-dimensional structures made of aligned electrospun nanofibers have also been fabricated. By using two or three pairs of patterned gold electrodes on an insulating substrate as a collector, Li et al. successfully stacked aligned nanofibers into multi-layered films, with the orientation of each layer rotated by $90^{\circ}$ or $60^{\circ}$ [93] (Fig. 2C). Wang et al. fabricated an electrospun tubular scaffold with circumferentially aligned PLLA nanofibers in the inner surface 
and a layer of polydimethylsiloxane (PDMS) coating on the outside for enhanced mechanical properties [94]. Wu et al. fabricated three-dimensional PCL nanofibrous tubular scaffolds with both circumferential and axial fiber orientations (Fig. 2D) [95]. It has been suggested that multidirectional nanofiber orientations can lead to nanofibrous scaffolds with different macroscopic properties.

[Insert Figure 2 here]

\subsection{Scaffolds comprised of multiphasic micro- or nanofibers}

The development of biomaterials and devices with precisely controlled and patterned surface/bulk microstructures has attracted great interest from biomedical engineers. First, such microstructures provide a useful platform to study the fundamental cell-cell and cell-biomaterial interactions. Knowledge gained would aid the design of advanced cell-biomaterial constructs for regenerative engineering. Second, finely tuned microstructures are critical in controlling the spatial distribution and programmable release of encapsulated signaling molecules, as well as guiding the organization of cells and neotissue growth.

A variety of multiphasic patterned micro- or nanofibrous structures have been developed via electrospinning and investigated for tissue engineering and drug delivery applications. One type of the micropatterned structures is termed Janus fibers, which contain two distinct phases of hemi-cylinders of a fiber with side-by-side compartment configurations [96]. Recently Lahann et al. developed multicompartmental microparticles, microcylinders, and microfibers by applying the side-by-side microfluid co-flow concepts to the electrospraying and electrospinning techniques [97-100]. In the co-jetting process, different polymer solutions are loaded in several side-by-side syringes and pumped together into a common tube to be electrosprayed or 
electrospun. High solution viscosity and low flow rates ensure a low Reynolds number and, thus, a laminar flow that is retained during the electrospraying/electrospinning process. As a result, distinct microcompartments are formed because minimal mass transfer occurs between the different streams of polymer solutions [100]. Lahann and colleagues have demonstrated the formation of a biphasic PLGA-based microfibers [101]. By controlling the chemical composition of the polymer in each compartment, a functional azide-peptide sequence was selectively attached either to one side of the Janus fiber or to both sides (Fig. 3A, 3B). NIH3T3 fibroblasts were capable of adhering only to the peptide-modified fiber compartment (Fig. 3C, 3D), suggesting that the anisotropic bicompartmental microfibers could be used for guided cell/tissue growth [101].

Recent advancements in electrospinning have also enabled researchers to fabricate multiphasic nanofibers exhibiting unique core-sheath structure. Coaxial electrospinning was developed as a useful technique to produce core-sheath nanofibers, which have shown great promise in the encapsulation and controlled release of drugs $[102,103]$. As the core fluid does not need to be electrospinnable, various proteins, growth factors, and genes that might otherwise denature in organic solvents can be dissolved in the core fluid, co-electrospun with the shell solution, and eventually incorporated into the core of the core-sheath structure [104, 105]. Rather than using a core-shell nozzle in the coaxial electrospinning process, one can also fabricate coresheath nanofibers through emulsion electrospinning using a conventional single-nozzle setup [106]. Core-sheath nanofibers fabricated from both techniques have been successfully used in drug delivery applications, with the benefits of attenuated initial burst release and versatile drug release profiles, e.g. dual drug delivery [107-109]. In one study, Wang et al. fabricated coresheath nanofibers consisting of a Naproxen-containing PCL sheath and a Rhodamine B- 
containing chitosan nanoparticle core (Fig. 3E, 3F). The core-sheath nanofibers possessed decoupled dual drug release capability and tunable drug release rates, with a higher release rate usually from the drug encapsulated in the nanofiber sheath due to shorter diffusional path [110].

More sophisticated multiphasic microfibers can be achieved by combining different electrohydrodynamic techniques. Lahann and colleagues have recently reported a novel jetting procedure that combines coaxial electrospinning conventionally used to produce core-sheath fibers with electrohydrodynamic co-jetting used to produce Janus fibers [111]. This approach allowed them to fabricate triphasic or quadriphasic microfibers with a Janus core and a polymer shell (Fig. 3G, 3H). These unique structures may find potential uses in drug delivery and regenerative medicine.

[Insert Figure 3 here]

\subsection{Nanofibrous scaffolds with gradients}

Gradient structures are ubiquitously present in the human body, especially within the musculoskeletal tissues. In addition, concentration gradients of signaling molecules play an important role in embryonic development, morphogenesis, angiogenesis, and tissue regeneration $[112,113]$. Therefore, it has become increasingly popular to develop artificial matrices with heterogeneous structures and properties for tissue engineering applications. Electrospun nanofibrous scaffolds exhibiting material or structural gradients have been developed to replicate the structures and functions of their natural counterparts. Liu et al. created a mineral-coated PLGA nanofibrous mat by immersing the PLGA mat into simulated body fluid (SBF). A mineral gradient along the long axis of the scaffold was obtained by varying the immersion time in the

SBF solution (Fig. 4A) [114]. Using a similar method, Shi et al. fabricated 
polymethylglutarimide nanofibrous scaffolds with a gradual change in fibronectin content along the long axis. NIH3T3 cells were able to respond to the protein gradient on the scaffold, with more cells spread on the region of higher fibronectin concentration [115]. Scaffolds with a polymer composition gradient can also be achieved by electrospinning. Du et al. fabricated graded chitosan/PCL blend nanofibrous scaffolds that exhibited chitosan-rich and PCL-rich portions by sequentially co-electrospinning chitosan and PCL solutions (Fig. 4B). Since chitosan is negatively charged and PCL is neutral, negatively charged heparin and heparin-binding vascular endothelial growth factor (VEGF) can be immobilized onto the electrospun scaffolds with a vertical gradient as well [116]. Bottino et al. fabricated a functionally graded membrane by a sequential multilayer electrospinning process [117]. In their study, a spatially designed multilayered nanofibrous membrane was fabricated with a core layer and two functional surface layers that interfaced with bone and epithelial tissues on two sides.

In addition to a material gradient, a structural gradient can also be obtained. One approach to creating graded fibrous scaffolds is to combine both nanofibers and microfibers into a stratified architecture. Using sequential electrospinning, Pham et al. fabricated multilayered scaffolds with alternating layers of PCL nanofibers and microfibers [118] (Fig. 4C-4F). The layered construct was designed to facilitate cellular infiltration into the scaffolds, while simultaneously providing nanofibers as a physical mimicry of ECM. Another approach to fabricating scaffolds with structural gradients is motivated by the stratified structures of natural tissues. The tendon-to-bone insertion site shows a gradual change in collagen type and collagen fiber orientation, from more aligned type I collagen in tendon to more random type II collagen in bone. Xie et al. created an "aligned-to-random" nanofibrous structure to mimic the insertion site using electrospinning equipped with a unique collector composed of two stapler-shaped metal 
frames separated by an air gap. Aligned PLGA nanofibers were formed in the air gap, while random nanofibers were formed on the metal frames at both ends [119, 120] (Fig. 4G).

[Insert Figure 4 here]

\subsection{Nanofibrous scaffolds with superior mechanical properties}

The conventional nanofiber mesh usually lacks appropriate mechanical properties to regenerate certain musculoskeletal tissues such as bone. It is critical to match the mechanical properties of the scaffolds with the tissue that they are designed to replace. Therefore, strategies for achieving mechanically competent nanofiber-based scaffolds are of great importance. Laurencin and colleagues reported the feasibility of developing a mechanically proficient nanofiber matrix using a biomimetic strategy [45]. A miscible polymer blend consisting of a dipeptide-based polyphosphazene and PLGA was electrospun to produce nanofibers with diameters ranging from $50-500 \mathrm{~nm}$ to imitate the dimensions of collagen fibrils in the ECM of natural bone. Biomimetic three-dimensional (3D) scaffolds were then fabricated by rolling the polymer-blend nanofiber mat in a concentric manner, creating an open central cavity. This formation replicates the bone marrow cavity as well as the lamellar structure of bone. The polyphosphazene/PLGA nanofiber scaffolds showed an average compressive modulus and strength of $151 \mathrm{MPa}$ and $1.5 \mathrm{MPa}$, respectively, both of which are in the mid-range of human trabecular bone.

\subsection{Nanofibrous scaffolds with large pores}

The electrospun nanofiber mesh, though highly porous, usually exhibits dense structure and contains very small pores that may potentially limit cell infiltration $[121,122]$. Therefore, 
creating nanofibrous scaffolds with appropriate pore size and/or geometry to facilitate cell ingrowth and infiltration has attracted research interest in the field of regenerative engineering. Several approaches have been used to manipulate the pore size of nanofibrous scaffolds, and thus manipulate cell infiltration. Baker et al. prepared aligned PCL/poly(ethylene oxide) (PEO) blend nanofibers by co-electrospinning the two polymers, where PEO served as the sacrificial fiber. Improved cellular infiltration was achieved by removing the PEO component which increased average pore size and porosity [123]. Phipps et al. fabricated biomimetic electrospun scaffolds consisting of PCL, collagen I, and nanoparticulate hydroxyapatite. They also found that introducing the sacrificial PEO fibers was an effective means to increase scaffold pore size (Fig. 5A, 5B) [124]. Lee et al. combined electrospinning with a salt leaching/gas forming process to obtain desired pore size. $\mathrm{NH}_{4} \mathrm{HCO}_{3} / \mathrm{NaCl}$ salt particles of $150-300 \mu$ m were sparsely scattered in the interlaminar layers of electrospun nanofiber sheets [125]. Micro-sized pores were obtained by removing the salt particles with water, which formed gaseous ammonia and carbon dioxide (Fig. 5C, 5D). From a different perspective, Blakeney et al. created a low density, uncompressed nanofibrous scaffold using a grounded spherical dish and an array of needle-like probes [126]. Unlike the traditional scaffolds with densely packed nanofibers (Fig. 5E), the uncompressed nanofibrous scaffold had less dense structure and larger pores, which increased cell penetration (Fig. 5F). As an alternative approach, nanofibrous scaffolds with larger pore sizes can be achieved by using fibers with larger diameters (Fig. 5G, 5H). Both experimental and statistical modeling results have revealed a positive correlation between fiber diameter and the pore size of the scaffolds using a variety of polymers [122, 127-129].

[Insert Figure 5 here] 


\section{Applications of nanofibers in musculoskeletal regenerative engineering}

\subsection{Nanofibers for the regeneration of bone}

Bone matrix typically makes up more than $90 \%$ of the volume of bone tissue, with the remainder made up mostly of cells and blood vessels [130, 131]. Bone matrix is a composite material primarily composed of type I collagen fibrils and nanohydroxyapatite. In order to replicate the natural matrix of bone, a variety of synthetic and natural polymers have been combined with hydroxyapatite and electrospun to produce nanofibrous composites as an artificial ECM for bone repair. Bhattacharyya et al. fabricated poly[bis(ethyl alanato)phosphazene]nanohydroxyapatite composite electrospun nanofibrous scaffolds with a hydroxyapatite content of 50-70\%, mimicking the composition of bone tissue [44]. Zhang et al. developed hydroxyapatite/chitosan nanofibrous scaffolds by first forming a hydroxyapatite/chitosan nanocomposite suspension in situ and then electrospinning the solution [48]. The composite nanofibrous scaffolds, with $30 \%$ hydroxyapatite, were shown to promote the proliferation and mineral deposition of human fetal osteoblasts.

Bone is one of the musculoskeletal tissues that have anisotropic structure and mechanical properties. Several techniques have been used to mimic the structural and mechanical anisotropy of bone tissue using electrospun nanofibers. The alignment of fibers has a profound effect on the mechanical properties of the nanofibrous scaffolds. Li et al. showed that a nanofibrous PCL scaffold with aligned fibers had a tensile modulus of 11.6MPa along the fiber direction compared to $2.1 \mathrm{MPa}$ for a non-aligned nanofibrous scaffold [132]. In addition, the prevailing nanofiber orientation has been shown to dictate cellular alignment and organization of actin filaments of human mesenchymal stem cells. Meng et al. fabricated both randomly-oriented and aligned PLGA/gelatin nanofibrous scaffolds [133]. Compared to the scaffolds with randomly-oriented 
nanofibers, the aligned nanofibrous scaffolds showed significantly increased elastic modulus and tensile strength. The aligned nanofibers guided cell growth along their longitudinal axes, which could be beneficial when utilizing these scaffolds for bone regeneration.

Pore size, porosity, and the degree of pore interconnectivity are three key features of tissue-engineered scaffolds that influence cellular activities. Studies have demonstrated that, while pore sizes of $5-15 \mu \mathrm{m}$ may be appropriate for neovascularization and fibroblast ingrowth, much larger pore sizes of $40-100 \mu \mathrm{m}$ and $100-350 \mu \mathrm{m}$ are required for osteoid ingrowth and for bone regeneration, respectively $[134,135]$. Although a conventional electrospun nanofibrous scaffold possesses high porosity and excellent pore interconnectivity, the pore size of the scaffold is sub-optimal for regenerating bone, as the small pore size hinders nutrient and oxygen transport, metabolic waste removal, and cellular infiltration. Therefore, fabricating a nanofibrous scaffold with larger pore size, without compromising its porosity and pore interconnectivity, has become crucial. Phipps et al. fabricated bone-mimetic electrospun scaffolds consisting of PCL, type I collagen, and nanohydroxyapatite [124]. Three different approaches to increasing the pore size of the scaffolds were investigated including partially digesting collagen I with protease, decreasing the fiber packing density, or introducing a sacrificial PEO component. Introduction of the sacrificial PEO polymer was found to be the most effective in increasing pore size. The scaffolds with larger pore sizes significantly promoted both mesenchymal stem cell (MSC) and endogenous cell infiltration during in vitro cell culture and calvarial organ cultures [124]. The average pore size of fibrous scaffolds increases with an increase in fiber diameter as previously mentioned. For instance, the average pore size of an electrospun PCL scaffold reached $45 \mu \mathrm{m}$ from $20 \mu \mathrm{m}$ when the fiber diameter was increased to $10 \mu \mathrm{m}$ from $4 \mu \mathrm{m}$ [118]. Traditionally, it has been accepted that nanofibers - due to their large surface area, high aspect ratio, and thus greater 
protein adsorption - promote cell adhesion and proliferation compared to microfibers, raising concerns with using microfibers to achieve larger pore sizes. However, the relationship between fiber diameter and cellular response has recently been shown to be more complex than originally thought. Several studies have indicated better cell proliferation on microfibers than on nanofibers, possibly due to the contact guidance phenomenon where cells are able to extend their lamellipodia along the microfilaments and infiltrate the larger pores associated with micro-scale fibers $[121,136]$. Ortiz, Laurencin, and co-workers combined microfibrous scaffolds with stem cells and a gene therapy technique, and studied the in vivo ectopic bone formation in

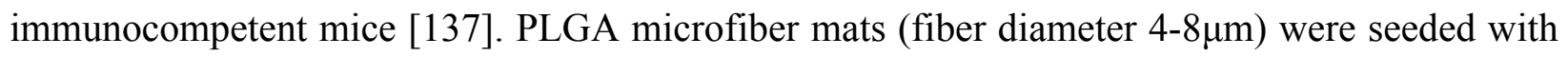
genetically modified MSCs expressing recombinant human bone morphogenetic protein -2 (rhBMP-2) and were transplanted into the thigh muscle of $\mathrm{C} 3 \mathrm{H} / \mathrm{HeN}$ female mice. The results showed that the regenerated bone tissue had similar mineral contents, overall microstructures showing lacunae and canaliculi, chemical compositions, and nanoscale topographical morphologies comparable to the native femoral bone adjacent to the transplantation site [137].

While non-load bearing bone defects can be relatively easily fixed with a wide selection of bone void filler materials, load bearing bone regeneration has presented more challenges to bioengineers and surgeons. It is generally accepted that a scaffold is more biocompatible if it more closely matches the mechanical properties of the native tissue. Inspired by the hierarchical bone structures, Laurencin et al. recently developed a mechanically competent scaffold mimicking both the bone marrow cavity and the lamellar structure of bone (Fig. 6A, 6B). Electrospun polyphosphazene/PLGA blend nanofibers were oriented in a concentric manner with an open central cavity, creating a biomimetic nanofibrous scaffold [45]. The potential of using this unique spiral scaffold for regenerating bone tissue was evaluated in vitro by monitoring 
cellular activity and mechanical performance. The polyphosphazene/PLGA blend nanofibers supported the adhesion, proliferation, and phenotype expression of primary rat osteoblasts. In vitro culture demonstrated that the biomimetic scaffolds promoted osteoblast proliferation and differentiation throughout the scaffold architecture, leading to a similar cell-matrix organization to that of native bone (Fig. 6C, 6D). The blend matrices enhanced cellular activities because the fiber diameter and porosity were optimized to provide more surface area for active cellular binding sites and for cell-material interactions. In addition, the scaffold seeded with cells was able to maintain its structural integrity and its initial high compressive modulus throughout the 28-day in vitro culture [45]. This was likely because the mineralized matrix produced by the seeded cells provided structural support to compensate for the loss of integrity due to degradation.

[Insert Figure 6 here]

\subsection{Nanofibers for the regeneration of soft musculoskeletal tissues}

\subsubsection{Cartilage Regeneration}

The repair of cartilage defects due to trauma or diseases is another grand challenge for orthopaedic surgeons. Articular cartilage is a structurally and functionally complex tissue consisting of highly specialized chondrocytes with various characteristics in different zones. The organization and composition of cartilage ECM vary spatially from the superficial to the deep zones. From the superficial zone to the deep zone of cartilage, the concentration of type II collagen decreases while that of proteoglycan increases [31]. The superficial zone is acellular, consisting of collagen fibrils with a course parallel to the articular surface; while the underneath, middle, and deep zones are formed by a dense, parallel array of collagen fibrils that are oriented 
perpendicular to the articular surface $[138,139]$. A calcified cartilage zone separates the deep zone (uncalcified cartilage) from the subchondral bone and is rich in type X collagen [32].

Nanofibrous scaffolds have been used in cartilage tissue engineering due to their structural similarity to the native cartilage ECM. Fabricated from either synthetic or natural polymers, these scaffolds have been shown to support the growth of chondrocytes and the chondrogenic differentiation of stem cells [140-142]. Scaffolds made of aligned nanofibers to mimic the collagen fibril organization of cartilage ECM have been investigated for cartilage repair. Wise et al. created aligned electrospun PCL scaffolds as an artificial ECM to replicate and regenerate the superficial zone of articular cartilage [143]. Baker et al. fabricated aligned electrospun nanofibrous scaffolds composed of $60 \%$ PCL fibers and $40 \%$ PEO fibers. The PEO fibers served as a sacrificial component, which led to the formation of macropores after being dissolved from the structure. Unlike typical nanofibrous scaffold systems, in which cell infiltration is dramatically limited, the electrospun scaffolds with enlarged pores hastened cell infiltration and the scaffold was completely infiltrated when cultured with fibrochondrocytes for 9 weeks. However, while fibrochondrocytes proliferated considerably and elaborated a robust collagen- and GAG-rich ECM, human MSCs showed limited division and matrix biosynthesis. This suggested that the 3D microenvironment has crucial control over cell fate processes of different types of cells [144]. Wimpenny et al. proposed a graded composite scaffold by electrospinning poly(L,D-lactic acid) (PLDLA) onto PLDLA microfibers rotating at a high speed to achieve nanofiber alignment [145]. The benefit of forming a graded composite is to combine the biomimetic architectures of nanofibers with the good mechanical properties of microfibers. In addition, the micrometer-size pores due to the presence of the microfibers may possibly facilitate cell migration and infiltration. The nano-microfibrous scaffolds were shown to promote 
the expression of chondrogenic markers such as type II collagen and aggrecan. This is likely because the size and alignment of the fibers were able to influence chondrocyte morphology, which is known to influence gene expression.

\subsubsection{Ligament and tendon Regeneration}

One of the most common surgical procedures performed is regeneration or replacement of ruptured/torn ligament or tendon tissues. For example, anterior cruciate ligament (ACL) rupture is one of the most common knee injuries related to disease or trauma. In addition, tendon damage is the most common injury in the young and physically active population [146]. For the past several decades, the use of autografts has been considered the gold standard for ACL reconstruction and tendon regeneration, while allograft tissue has also been commonly used. The use of tissue grafts has a high success rate; however, it is associated with limitations such as donor site pain and morbidity with autografts and potential disease transmission with allografts. Consequently, tissue engineering has become a promising alternative approach for the regeneration of ligament and tendon tissues by using specifically designed scaffolds, cells, and/or growth factors [147, 148].

Electrospun nanofibrous scaffolds have been investigated to repair ligament and tendon by providing an artificial ECM that mimics the collagen fiber bundles present in the natural tissues. In our laboratory, we fabricated an electrospun PLGA nanofibrous scaffold as a novel therapeutic strategy to support and accelerate the healing of a torn rotator cuff [38]. The efficacy of the PLGA nanofibrous scaffold to accelerate the healing rate of a tendon defect was evaluated in an original rodent model. The results showed a significant increase in the Young's modulus for the group that had received augmentation with the nanofibrous scaffold compared to the 
group that had received only primary supraspinatus repair. In another study, a PLGA nanofibrous scaffold, combined with adipose-derived stem cells and growth/differentiation factor-5 (GDF-5), was evaluated for tendon tissue engineering [39]. Gene expression of the neotendon marker, scleraxis, was upregulated seven- to eightfold at 1 week with GDF- 5 treatment when the cells were cultured on the 3D PLGA nanofibrous electrospun scaffold. Expression of scleraxis on the 3D PLGA scaffolds was also significantly higher at 2 weeks compared to expression of the marker on 2D PLGA films with or without GDF-5 treatment. In addition, expression of the genes that encode type I collagen, the major ECM protein component of tendon tissue, was significantly higher for cells on the 3D nanofibrous scaffold than on the 2D films irrespective of GDF-5 treatment. The collective effects seen with the 3D-structured scaffold and the GDF-5 treatment suggest that both mechanical and biochemical signals are essential for cellular differentiation on bioengineered scaffolds.

Normal healthy tendons are mainly composed of parallel arrays of closely-packed collagen fibers, which leads to highly anisotropic mechanical properties. Therefore, scaffolds made of aligned nanofibers are attractive candidates in tendon and ligament tissue engineering, as they mimic the anisotropic structure of the native tissues. A number of studies have investigated the effects of nanofiber diameter and alignment on the cellular behaviors of both undifferentiated stem cells and committed fibroblasts. Bashur et al. fabricated electrospun polyurethane meshes consisting of either aligned or randomly-oriented nanofibers with diameters in the range of $280 \mathrm{~nm}$ to $2.3 \mu \mathrm{m}$ [149]. Bone marrow stromal cells were seeded onto the polymer meshes, and the data suggested that the formation of a ligament-like tissue was enhanced on the surfaces of scaffolds fabricated from aligned submicron fibers. Lee et al. studied the effects of fiber alignment and direction of mechanical stimuli on ECM generation by human ligament 
fibroblasts [60]. Significantly more collagen was synthesized on scaffolds with aligned nanofibers than on those with randomly-oriented nanofibers. In addition, the ligament fibroblasts were shown to be more sensitive on the parallel-aligned nanofibers with an externally applied strain in the same direction. Yet in another study, Yin et al. investigated the effect of nanofiber alignment on the regulation of tendon stem cell differentiation [150]. Human tendon stem/progenitor cells (hTSPCs) were seeded onto aligned or randomly-oriented poly(L-lactic acid) nanofibers. Aligned nanofibers were shown to increase the expression of tendon-specific genes compared to randomly-oriented nanofibers in both normal and osteogenic media. In vivo experiments further showed that the aligned nanofibers induced the formation of spindle-shaped cells and tendon-like tissue. On the other hand, randomly-oriented nanofibrous scaffolds induced osteogenesis as evidenced by enhanced alkaline phosphatase activity and alizarin red staining, while the aligned scaffold hindered the osteogenic processes of the hTSPCs. These seemingly contradicting data indicate that aligned nanofibers promote differentiation of tendon stem/progenitor cells into the tenogenic lineage, while randomly-aligned nanofibers promote differentiation into the osteogenic lineage. The topographies of nanofibers have an influence on cell attachment, orientation, and morphology, which all play roles in determining gene expression. Yin et al. suggest that attachment to the aligned fibers stimulates tenogenic lineage through physical cues and integrin-mediated signaling, since this observation was maintained even in the presence of osteoinductive medium.

\subsubsection{Regeneration of Soft-to-Hard Tissue interface}

The regeneration of the ligament/tendon-to-bone interface remains a challenging task for both scientists and surgeons. Ligament and tendon tissues have complex morphologies at their 
bone insertion sites, which include zones transitioning from ligament, to stress-distributing fibrocartilage, to calcified cartilage, and then merging into bone. The cells and ECM vary dramatically in these four zones. The ligament/tendon zone consists of fibroblasts, ligament cells, or tenocytes embedded in parallel collagen fibril bundles, primarily made of type I collagen. The fibrocartilage zone is approximately 150 to $400 \mu \mathrm{m}$ in width. The tissue in this zone is primarily composed of collagen type II (typically seen in articular cartilage) with significant amounts of aggrecan. The cells are round, aligned in pairs or in rows, and lie in lacunae of the ECM. Separated from the fibrocartilage by a perpendicularly traversing line or tidemark, calcified fibrocartilage ranges from 100 to $300 \mu \mathrm{m}$ in width. Calcified fibrocartilage is primarily composed of collagen type II and large amounts of collagen type X. Collagen fibrils are less aligned in this zone than in the fibrocartilage and ligament zones. In the fourth zone, bone is composed of a highly mineralized collagen type I matrix containing osteoblasts, osteoclasts, and osteocytes. It is clear that the ligament/tendon-to-bone insertion site exhibits gradients in ECM compositions, a gradual increase in mineralization, and a gradual decrease in tissue organization from ligament/tendon to bone $[151,152]$.

To mimic the different collagen fiber organizations in both ligament/tendon and bone, Xie et al. created a unique electrospun nanofibrous scaffold with one portion of aligned PLGA nanofibers and a second portion of randomly-oriented nanofibers [119]. The aligned portion of the scaffold was designed to mimic the high level of collagen fiber alignment that is responsible for the high tensile modulus and strength in a normal tendon. Meanwhile, the random portion was designed to reproduce the less ordered organization of collagen fibers in bone tissue. Tendon fibroblasts were cultured on the gradient scaffold. The tendon cells on the aligned nanofibers showed a cytoskeleton consisting of actin filaments aligned with the long axis of the fibers and 
produced type I collagen, indicating a high degree of organization. In contrast, the cells on the random nanofibers showed a disorganized actin cytoskeleton and a random distribution of type I collagen [119]. These observations indicate that nanofiber alignment can be modified in order to promote the cellular morphologies naturally present at tendon-to-bone insertion sites.

Efforts have also been taken to develop scaffolds that possess continuous compositional gradients as artificial matrices to regenerate ligament/tendon-to-bone tissue interfaces. To mimic the gradual increase in mineralization, Li et al. fabricated a nanofibrous PLGA mat with a linear gradient of calcium phosphate by electrospinning and a subsequent biomineralization process [153]. The mineral gradient contributed to a gradient in the stiffness and biological functioning of the scaffold. MC3T3 osteoblastic cells preferentially adhered to, and proliferated in, regions with higher calcium phosphate content along the gradated scaffold. Samavedi et al. developed a continuously graded mesh by co-electrospinning nanohydroxyapatite/polycaprolactone and poly(ester urethane) urea elastomer solutions. The nanofiber mesh showed gradients in polymer compositions and hydroxyapatite content. The presence of the hydroxyapatite gradient aided in selective mineralization of the nanofibers when soaked in a concentrated simulated body fluid solution, mimicking the ligament-to-bone tissue interface [154].

\subsubsection{Nerve Regeneration}

Peripheral nerve injuries caused by trauma or diseases often necessitate the use of nerve grafts to guide the direction of the axon from the proximal to the distal nerve ends. Currently, an autograft is regarded as the principal method for nerve regeneration; however, it suffers from limited supply, donor site morbidity, and the risk of neuroma formation [155]. Therefore, alternative nerve grafts fabricated from biodegradable polymers in the form of porous scaffolds 
have attracted research interest and have been evaluated for their efficacy in neural tissue engineering [156-158].

In the development and regeneration of the nervous system, contact guidance has been shown to play an important role in response to an injury in the peripheral nervous system. It has been reported that immature neurons in the medulla oblongata migrate parallel to oriented fibers [159]. Evidence also shows that neurons migrate along tracts of glial cells, or oriented ECM fibers in some instances, during the development of nervous system [160, 161]. Since directed growth plays a key role in the regeneration of injured peripheral nerves, a great number of studies have been conducted recently to assess the reaction of neural stem cells, neurons, and glial cells on anisotropic structures carrying topographical cues provided by aligned electrospun nanofibers. Yang el al. seeded neural stem cells on PLLA scaffolds consisting of aligned nanofibers. They observed that the direction of neural stem cell elongation and neurite outgrowth was parallel to the direction of the aligned nanofibers, although the cell growth rate was independent of fiber orientation [56]. The importance of nanofiber alignment to direct neurite outgrowth and to regenerate nerve defects has been further demonstrated by a number of other studies. Wang et al. evaluated the growth patterns of dorsal root ganglia (DRG) and rat Schwann cells on highly aligned PLLA nanofibrous scaffolds containing crossing fibers. Neurites on these scaffolds were not only directed down the axis of the aligned fibers, but they also grew along the crossed fibers. These crossed fibers sometimes stopped further axonal extension [69]. Kim et al. fabricated both uniaxially and randomly aligned nanofibrous films by electrospinning poly(acrylonitrile-co-methylacrylate) and seeded the films with DRG. In vitro results showed that neurite outgrowth and Schwann cell migration from the DRG extended unidirectionally parallel to the fiber alignment, while outgrowth and cell migration was randomly distributed on 
the random nanofibrous films. The fibrous scaffolds were also tested for their ability to regenerate a long, peripheral nerve defect in rats. Interestingly, the aligned, but not the randomly oriented nanofibrous constructs, successfully promoted the regeneration of axons across a $17 \mathrm{~mm}$ long nerve gap with the reinnervation of muscles and reformation of neuromuscular junctions [162].

In order to best mimic the hierarchical structures that occur in the mature peripheral nervous system, many studies have focused on developing 3D guidance conduits for nerve regeneration. An ideal nerve conduit should possess a biodegradable and porous channel wall, have the ability to incorporate and deliver signaling molecules and/or supportive cells, and have intraluminal channels to mimic the structure of nerve fascicles [163]. These characteristics would allow the nerve conduits to direct the sprouting of axons from the proximal to the distal ends and reduce the infiltration of scar tissue. Electrospun nanofibrous tubular structures consisting of either random nanofibers, aligned nanofibers, or a bilayered structure with aligned nanofibers in the inner layer and random nanofibers in the outer layer have been suggested as potential nerve conduits for nerve regeneration [164]. Wang et al. fabricated tubular chitosan nanofiber mesh with or without orientation and bilayered tube with an inner layer of oriented nanofibers and an outer layer of randomized nanofibers (Fig. 7A-7C). These tubes were then bridge-grafted into a $10 \mathrm{~mm}$ rat sciatic nerve defect. Thirty weeks after implantation, the tube graft with random nanofibers collapsed slightly and the regenerated axons scattered in the loose connective tissue of the lumen, with limited blood vessel formation (Fig. 7D). In contrast, the chitosan tube with oriented nanofibers and the bilayered tube were able to maintain the inner space and form new nerves resembling the isograft. In addition, many large diameter and middle-sized axons matured to mass in the oriented and bilayered tube grafts, respectively (Fig. 7E, 7F) [165]. The same 
group demonstrated that incorporation of $\beta$-tricalcium phosphate particles into the chitosan nanofibrous tube was able to induce electrical polarization and further enhance nerve regeneration [166]. Koh et al. developed a bilayered nerve conduit made out of PLLA nanofibers, which were longitudinally aligned in the lumen and randomly oriented on the outer surface. The construct also contained an intra-luminal guidance channel made of bundles of aligned PLGA nanofibers with encapsulated nerve growth factor. The introduction of the intra-luminal guidance channel increased the mechanical stability of the nerve conduit and provided a guidance substrate for axonal outgrowth, mimicking the basal lamina structures of the autologous nerve graft. The nerve grafts were evaluated using a rat sciatic nerve defect model. Results showed that functional recovery, as evidenced by muscle reinnervation and withdrawal reflex latency, was improved with the use of the nerve construct; however, the axon density was still highest in the autograft group [167].

[Insert Figure 7 here]

\subsubsection{Skeletal Muscle Regeneration}

Skeletal muscle injuries due to sports-related trauma or other diseases present great challenges in primary care and sports medicine. In major injuries where the muscle structure is irreversibly damaged, surgical interventions such as using autologous tissue to restore muscle functions have been commonly used in the clinic. However, the use of muscle autografts is inevitably limited by tissue availability and donor site morbidity. Therefore, engineered scaffolds mimicking the structure of native muscle tissue may overcome the limitations of muscle autografts and provide a successful option for muscle regeneration. It is well known that functional skeletal tissue consists of highly oriented myofibers derived from multinucleated 
myotubes, which are formed by the fusion of mononucleated myoblasts [168]. Thus, an artificial scaffold that guides muscle cell alignment, allowing for oriented myotube formation via topographical and/or chemical cues, is believed to be critical in musculoskeletal myogenesis.

Electrospun nanofibrous scaffolds are intrinsically advantageous as artificial matrices for muscle regeneration. A large number of electrospinnable polymers allows for the screening and selection of a graft material with suitable biological and mechanical properties that match those of skeletal muscle. In addition, the electrospinning process permits the formation of unidirectional nanofibers, which guide the growth of different types of cells. Aligned nanofibrous scaffolds fabricated from both synthetic and natural polymers have been evaluated for skeletal muscle regeneration. Aviss et al. synthesized aligned PLGA nanofibrous scaffolds and evaluated the growth and functions of $\mathrm{C} 2 \mathrm{C} 12$ murine myoblasts. The myoblasts not only aligned themselves on the oriented nanofibrous scaffolds, but also produced significantly higher expression of the differentiation marker, fast myosin heavy chain, than those on the random nanofibrous scaffolds [169]. Cooper et al. investigated the effect of chitosan-PCL nanofiber alignments on the behavior of $\mathrm{C} 2 \mathrm{C} 12$ murine myoblasts. It was found that the fiber alignment significantly enhanced myoblast proliferation and promoted aligned myotube formation in the nanofiber orientation. The muscle differentiation-specific genes, myogenin, troponin $\mathrm{T}$, and myosin heavy chain, were significantly up-regulated in muscle cells on the aligned nanofibrous scaffolds compared to the random nanofibrous scaffolds, confirming the ability of aligned chitosan-PCL nanofibers to enhance muscle cell differentiation [170]. In another study, Choi et al. investigated whether electrospun PCL-collagen nanofibers could guide morphogenesis of human skeletal muscle cells and enhance cellular organization. Both the aligned and randomly oriented nanofiber meshes were able to maintain the phenotype of the human skeletal muscle 
cells as evidenced by the positive immunofluorescent staining of desmin, myosin heavy chain, and sarcomeric actin. The cells and myotubes were arranged along the longitudinal axis of the aligned nanofiber direction (Fig. 8E-8G), while the myotubes were mostly scattered in all directions on the randomly oriented nanofiber meshes (Fig. 8A-8C). In addition, the cytoskeletal protein, actin, appeared disordered on the randomly oriented nanofiber structures (Fig. 8D); whereas the actin filaments were well organized along the nanofiber direction on the aligned nanofiber structures (Fig. 8H). Furthermore, although the nanofiber alignment did not affect diameter of the formed myotubes, the average length of the myotubes on the aligned nanofibrous meshes was more than twice the length of the myotubes on the randomly oriented nanofibrous meshes [87].

[Insert Figure 8 here]

\section{Nanofiber-Based Delivery of Signaling Molecules for Musculoskeletal Tissue Regeneration}

\subsection{Growth Factor Delivery}

During the last several years, musculoskeletal regenerative engineering using electrospun nanofibrous scaffolds combined with growth factors has emerged. These novel scaffolds provide both a biomimetic ECM for cell adhesion and powerful localized signaling moieties, with prolonged biological effects, to direct cellular behaviors [171-174]. Growth factors can be loaded into electrospun nanofibrous scaffolds using a variety of methods, including physical adsorption, covalent linking, and encapsulation (Fig. 9) [171, 175, 176]. In addition, hydrogels, microparticles, nanoparticles, and other forms of drug delivery devices can be hybridized with nanofibers for specific biomedical applications $[177,178]$. However, it should be noted that protein growth factors are easily denatured during the loading process due to the use of harsh 
organic solvents, cross-linking reagents, low/high $\mathrm{pH}$ environments, and high temperatures. Thus, caution must be taken during the incorporation process [171].

[Insert Figure 9 here]

Growth factors are usually referred to as large polypeptides that provide the driving forces for many cellular events including proliferation and differentiation [179]. Growth factors also play a dominant role in musculoskeletal tissue regeneration [180]. Therefore, researchers have actively searched for appropriate growth factors to stimulate musculoskeletal regeneration. Today, bone morphogenetic proteins (BMPs) are considered especially important growth factors since these multi-functioning proteins have been shown to be osteoinductive, i.e. they have the capability to induce bone formation in ectopic sites [181]. To date, several devices containing BMP-2 and BMP-7 have been approved by the U.S. Food and Drug Administration for a number of clinical applications including fracture healing, non-union repair, long bone defect repair, spinal fusion, and alveolar ridge and maxillary sinus augmentation [182, 183]. BMPs have also been incorporated into polymeric nanofibrous scaffolds for bone tissue regeneration and repair. For instance, the Palleta group has explored the delivery of BMP-2 within a PLLA based nanofiber scaffold for in vivo bone repair and regeneration [175]. They directly incorporated recombinant BMP-2 into a PLLA solution and then electrospun the solution into nanofibers. Their data revealed that the addition of BMP-2 significantly improved in vivo bone regeneration in a rat critical sized calvarial defect model, therefore showing the efficacy of BMP-2 within the nanofiber scaffold. Although the release kinetics of BMP-2 from the scaffold and the mechanism of action were not reported, the PLLA based nanofibers were proposed as efficient carriers of BMP-2 [175]. Given that protein-based growth factors are readily degraded in organic solvents [184], polymers that are soluble in aqueous-based solutions are favorable for growth factor 
delivery [171]. For instance, the Kaplan group fabricated a functionalized nanofiber scaffold system by incorporating recombinant BMP-2 into silk polyethylene oxide solution. Their results demonstrated that the exogenous BMP-2 could significantly enhance the in vitro osteogenic response of human mesenchymal stem cells [185].

In addition to BMPs, other growth factors such as basic fibroblast growth factor (bFGF), vascular endothelial growth factor (VEGF), nerve growth factor (NGF), and platelet-derived growth factor (PDGF) have been introduced into nanofibrous scaffolds to enhance their therapeutic efficacy for musculoskeletal regenerative engineering (Table 1). Casper et al. conducted a study using low molecular weight heparin (LMWH) to incorporate growth factor bFGF onto the surface of poly(ethylene glycol) (PEG) based nanofibers [186]. Their data indicated that LMWH was retained in the nanofibers for at least 14 days, and the binding of the bFGF to the PEG-LMWH functionalized nanofibers was found to be stronger than to those functionalized with LMWH alone. This indicates that PEG-LMWH nanofibers could allow for bFGF delivery over the long period of time needed for musculoskeletal regeneration [186]. Apart from regenerating bone tissue, growth factor-loaded nanofibrous scaffolds have been shown to influence the regeneration processes of other musculoskeletal tissues including peripheral nerve, tendon, and skin. Zhang et al. encapsulated NGF into electrospun silk fibroin/P(LLA-CL)blended nanofibrous scaffolds. Their data suggested that the NGF released from the nanofibers could effectively promote the regeneration of peripheral nerve in a rat sciatic nerve injury model [187]. Manning et al. developed a novel scaffold system that they claimed is "capable of delivering growth factors and cells in a surgically manageable form for tendon repair" [188]. They incorporated PDGF and adipose-derived stem cells (ASCs) into a heparin/fibrin-based hydrogel delivery system and subsequently hybridized the hydrogel with PLGA-based 
nanofibers. Their data revealed that delivering PDGF together with ASCs could significantly improve tendon healing in a large animal tendon model [188]. Xie et al. recently developed a "dual growth factor releasing nanoparticle-in-nanofiber system" for skin regeneration [189]. In their system, PDGF-loaded PLGA nanoparticles were embedded into VEGF-incorporated chitosan/PEO-based electrospun nanofibers. The release profile showed a relatively fast release of VEGF from the nanofibers and a substantial sustained release of PDGF from the nanoparticles. Moreover, their novel scaffold system supported fibroblast growth in vitro, as well as in vivo wound healing in a full thickness rat skin wound model [189].

Table 1.

[190],[175],[185],[186],[191],[192],[187],[193],[188],[189],[194]

Although growth factors show potential for use in tissue regeneration and repair, they have various drawbacks. In general, protein instability, high manufacturing cost, and immunogenicity are the common problems associated with protein-based therapeutic strategies. Therefore, new strategies that utilize alternative forms of bioactive factors, such as small bioactive molecules, to obviate these drawbacks have the potential to revolutionize the field of musculoskeletal regenerative engineering.

\subsection{Small Molecule Delivery}

The use of biologically active small molecules is emerging in the area of musculoskeletal regenerative engineering because small molecules do not possess many of the limitations associated with protein-based growth factors, including BMPs [12, 182-184, 195, 196]. For instance, one of the benefits of utilizing small molecules is that they are unlikely to pose a significant issue regarding immunogenicity since their molecular sizes are too small to elicit an 
immune response effectively [197]. In addition, small molecules are often inexpensive and chemically stable when compared to recombinant protein growth factors [198]. It should be noted that the molecular weights of small molecules are less than 1,000 Daltons; therefore, many of them are able to diffuse into cells and interact with specific intracellular protein receptors. These specific small molecule-protein interactions can trigger signaling transduction cascades that lead to a desired path of cellular differentiation. For instance, a small molecule could be identified to activate signaling pathways that stimulate osteoblast-associated gene expression and matrix mineralization, which are processes associated with bone formation [199]. In fact, data from our group and others demonstrated that small molecule cyclic adenosine monophosphate (cAMP) analogs were able to induce in vitro and in vivo bone formation through the Protein Kinase A (PKA)/cAMP response element-binding protein (CREB) signaling mechanism [200203]. It is also worth noting that the advances in high throughput screening technologies have yielded a large number of other osteoinductive small molecules in the past decade [176]. Taken together, these observations suggest the prospective future of using small molecules for musculoskeletal regenerative engineering, especially for bone tissue repair and reconstruction.

While promising, the major concern of using small molecule technologies is the interactions with non-target tissues or organs [184]. Therefore, it is essential to design small molecule delivery systems for tissue regeneration that can effectively localize and sustain controlled release of the small molecule at a specific site $[174,176,184]$. Biodegradable nanofiber-based polymeric scaffolds have been proposed as controlled drug delivery vehicles of small molecules for regenerating skeletal tissues. For instance, Kouhi et al. incorporated the osteoinductive small molecule simvastatin into electrospun PCL nanofibers and evaluated its potential for bone tissue engineering applications. The drug release kinetics and the in vitro 
bioactivity were evaluated in simulated body fluids [204]. Their data revealed that the small molecule simvastatin was released in a controlled manner, and a layer of apatite was formed on the nanofiber surface [204]. Similarly, Singh et al. incorporated the osteoinductive small molecule resveratrol into PCL nanofibers and evaluated its bioactivity in osteoprogenitor MC3T3-E1 cells [205]. Their results indicated that the resveratrol-loaded PCL nanofiber group showed a significant increase in mineralized matrix deposition compared to the unloaded control group [205]. However, in vivo studies of osteogenesis in the presence of these small moleculeloaded PCL nanofiber scaffolds were not reported in either paper. Recent studies conducted by Das et al. demonstrated that osteoinductive small molecule FTY720-loaded nanofibers composed of PCL and PLGA were shown to increase new bone and microvascular formation in a rat mandibular defect model [206]. Specifically, at week 12 after the implantation, FTY720loaded nanofiber groups demonstrated significant new bone formation and new blood vessel formation within the defect area [206]. Taken together, these studies suggest that small molecules in combination with nanofibers have the tremendous potential to revolutionize strategies for bone repair and regeneration.

Other than bone tissue, musculoskeletal tissues also include muscles, nerves, cartilage, tendons, joints, and ligaments. Although the utilization of small bioactive molecules for regenerating muscle, cartilage, tendons, and nerves has been reported [12, 207], to our knowledge, literature reporting the nanofiber-based delivery of small molecules for regenerating these musculoskeletal tissues is very limited. Therefore, further research is needed to investigate the appropriate choice of small molecule, loading and delivery method, dosage requirement, and pre-clinical animal models in order to provide the foundation for future clinical usage in musculoskeletal regeneration. 


\section{Challenges in Electrospinning and Nanofibrous Scaffolds for Tissue Regeneration}

Electrospinning is a convenient and versatile technique to fabricate nanofibers and nanofibrous scaffolds for tissue engineering applications. By altering the polymer solution properties and a number of processing parameters such as voltage, flow rate, distance between the needle tip and the collector, and the type of spinneret and collector, one can fabricate a variety of nanofiber assemblies. Nanofibrous structures are highly porous, possess extremely high specific surface area, and mimic the native microenvironments that cells face in vivo. These attributes make nanofiber scaffolds highly advantageous in tissue engineering and drug delivery applications.

Nevertheless, challenges remain when applying the electrospinning process and electrospun nanofibrous scaffolds to musculoskeletal tissue regeneration. The main challenge encountered during fabrication is the inability to control fiber size and arrangement for optimized cell infiltration. Aligned nanofibers are especially ideal for tissue regeneration applications as research has shown that cells tend to elongate, proliferate, and differentiate well along the aligned fibers $[56,69,87,133,143,149,162,169,170]$. However, methods to obtain a large area of consistent arrangement need to be refined. A rotating drum is the common collector used to create aligned nanofibers, but the rotation speed needs to be finely adjusted for differences in fiber diameter [208]. Increased fiber diameter or introduction of a sacrificial polymer component is often utilized to increase pore size in order to enhance cell infiltration $[118,121-124,127-129$, $136,144]$; however, increased pore size is also associated with decreased mechanical integrity $[209,210]$. 
Another challenge faced when creating nanofibrous scaffolds for musculoskeletal tissue regeneration is the development of suitable mechanical properties. For example, mineral gradients are often introduced to the surfaces of fibers in order to mimic mineralized bone tissue. Unfortunately, the resulting mechanical strength is often not comparable to that of bone. Carefully modifying the ion concentrations of the mineral coating solution can enhance modulus and decreased toughness, providing mechanical properties similar to those of bone tissue [211]. Since polymeric nanofiber scaffolds act as temporary templates at sites of tissue regeneration, it is important that the scaffolds maintain this structural integrity for the time needed for cells to infiltrate and secrete their own ECM. The issue of scaffold shrinkage during degradation has prompted researchers to fabricate novel patterns of electrospun polymers, such as nestlikepatterned PLGA matrices, to maintain scaffold morphology and strength [212].

Although PLGA is the most widely used polymer for electrospinning nanofibrous scaffolds for tissue regeneration, researchers are exploring other polymer options to provide unique features to suit their desired applications. Since many polymer solutions are not easily spun due to characteristics such as low conductivity and high surface tension, special methods that utilize an electrospinnable carrying solution can be explored to fabricate double-layered fibers [208]. The carrier layer can be subsequently removed, leaving the desired polymer nanofiber intact. Overall, the development of three-dimensional nanofibrous scaffolds that exhibit all of the properties necessary to mimic musculoskeletal tissue and facilitate cell infiltration still needs to be optimized for successful application in the clinic. 


\section{Conclusions and Future Outlook}

The emergence of regenerative engineering provides tissue engineers with invaluable tools to achieve the repair and regeneration of musculoskeletal tissues using biomaterials, cells, and growth factors/signaling molecules. In the realm of regenerative engineering, we believe that future research should focus on advanced materials science, stem cells, developmental biology, and strategies to integrate these components into a functional biological system. Creating nanoscale scaffolds with nanotopographical features has been suggested as a key to successfully regenerating musculoskeletal tissues by mimicking the natural microenvironments that cells face in the body. In this review, the use of electrospun nanofibers for musculoskeletal regenerative engineering was discussed. A brief description on the electrospinning process and the parameters of manipulating nanofiber properties was provided. Furthermore, the fabrication processes and applications of a number of advanced functional nanofibrous scaffolds were presented. Specifically, this review discussed anistropic nanofibrous scaffolds made of aligned nanofibers and nanofibrous scaffolds that showed chemical/structural gradients, and/or other macroscopic features to promote cell infiltration and mimic natural extracellular matrices. This review also discussed nanofibrous scaffolds that possessed superior mechanical properties for regenerating both hard and soft musculoskeletal tissues. Finally, the use of nanofibers as carriers for growth factors and clinically relevant small molecules for tissue regeneration was discussed. Future research in this highly translational field should focus on the convergence of several disciplines including biomimetic nanofibrous scaffold fabrication, stem cells, and manipulation of signaling pathways particularly with small molecules to regenerate complex human tissues and organs. 


\section{Acknowledgements}

The authors acknowledge the funding from the National Science Foundation (NSF-EFRI 1332329) and the Presidential Award for Excellence in Science, Engineering, and Math Mentoring (NSF DUE0834313). We also wish to thank the Raymond and Beverly Sackler Center for Biomedical, Biological, Physical and Engineering Sciences Foundation for supporting our Institute. Dr. Laurencin was previously the recipient of a Presidential Faculty Fellow Award from the National Science Foundation.

\section{References}

[1] Bishop GB, Einhorn TA. Current and future clinical applications of bone morphogenetic proteins in orthopaedic trauma surgery. Int Orthop 2007;31:721-7.

[2] Faulkner A. Usership of regenerative therapies: Age, ageing and anti-ageing in the global science and technology of knee cartilage repair. Technoll Forecast Soc Change. 2014;DOI: 10.1016/j.techfore.2014.02.020 (10 pp)

[3] Freedman KB, D’Amato MJ, Nedeff DD, Kaz A, Bach BR. Arthroscopic anterior cruciate ligament reconstruction A metaanalysis comparing patellar tendon and hamstring tendon autografts. Am J Sports Med 2003;31:2-11.

[4] A Cooper J, Ferraro B, Christensen A. Recent Advancements in Soft Tissue Regeneration. Recent Pat Biomed Eng 2013;6:22-8.

[5] Laurencin CT, Ambrosio A, Borden M, Cooper Jr J. Tissue engineering: orthopedic applications. Annu Rev Biomed Eng 1999;1:19-46.

[6] Laurencin C, Khan Y, El-Amin SF. Bone graft substitutes. Expert Rev Med Devices 2006;3:49-57.

[7] Langer R, Vacanti J, P. Tissue engineering. Science 1993;260:920-6.

[8] Spector M. Biomaterials-based tissue engineering and regenerative medicine solutions to musculoskeletal problems. Swiss Med Wkly 2006;136:293-301.

[9] Muschler GF, Nakamoto C, Griffith LG. Engineering principles of clinical cell-based tissue engineering. J Bone Joint Surg 2004;86:1541-58. 
[10] Pei M, Seidel J, Vunjak-Novakovic G, Freed L. Growth factors for sequential cellular deand re-differentiation in tissue engineering. Biochem Biophysl Res Commun 2002;294:149-54.

[11] Laurencin CT, Khan Y. Regenerative engineering. Sci Transl Med 2012;4:160ed9/1-3.

[12] Lo KW-H, Jiang T, Gagnon KA, Nelson C, Laurencin CT. Small-molecule based musculoskeletal regenerative engineering. Trends Biotechnol 2014;37:74-81.

[13] Rho J-Y, Kuhn-Spearing L, Zioupos P. Mechanical properties and the hierarchical structure of bone. Med Eng Phys 1998;20:92-102.

[14] Laurencin CT, Kumbar SG, Nukavarapu SP. Nanotechnology and orthopedics: a personal perspective. Wiley Interdiscipy Rev Nanomed Nanobiotechnol 2009;1:6-10.

[15] Bettinger CJ, Langer R, Borenstein JT. Engineering substrate topography at the micro-and nanoscale to control cell function. Angew Chem Int Ed 2009;48:5406-15.

[16] Li J-R, Shi L, Deng Z, Lo SH, Liu G-y. Nanostructures of designed geometry and functionality enable regulation of cellular signaling processes. Biochemistry 2012;51:5876-93.

[17] Mendes PM. Cellular nanotechnology: making biological interfaces smarter. Chem Soc Rev 2013;42:9207-18.

[18] Loesberg W, Te Riet J, van Delft F, Schön P, Figdor C, Speller S, van Loon J, Walboomers XF, Jansen JA. The threshold at which substrate nanogroove dimensions may influence fibroblast alignment and adhesion. Biomaterials 2007;28:3944-51.

[19] Nair LS, Bhattacharyya S, Laurencin CT. Development of novel tissue engineering scaffolds via electrospinning. Expert Opin Biol Ther 2004;4:659-68.

[20] Pham QP, Sharma U, Mikos AG. Electrospinning of polymeric nanofibers for tissue engineering applications: a review. Tissue Eng 2006;12:1197-211.

[21] Schindler M, Ahmed I, Kamal J. A synthetic nanofibrillar matrix promotes in vivo-like organization and morphogenesis for cells in culture. Biomaterials 2005;26:5624-31.

[22] Jaworek A, Sobczyk A. Electrospraying route to nanotechnology: an overview. J Electrostat 2008;66:197-219.

[23] Rutledge GC, Fridrikh SV. Formation of fibers by electrospinning. Adv Drug Deliv Rev 2007;59:1384-91.

[24] Cooley JF. Apparatus for electrically dispersing fluids. US 692631, 1902. 
[25] Morton WJ. Method of dispersing fluids. US 705691, 1902.

[26] Doshi J, Reneker DH. Electrospinning Process and Applications of Electrospun Fibers. J Electrostat 1995;35:151-60.

[27] Reneker DH, Chun I. Nanometre diameter fibres of polymer, produced by electrospinning. Nanotechnology 1996;7:216-23.

[28] Taylor G. Disintegration of water drops in an electric field. Proc Royal Soc Lond Ser A 1964;280:383-97.

[29] Yarin AL, Koombhongse S, Reneker DH. Taylor cone and jetting from liquid droplets in electrospinning of nanofibers. J Appl Phys 2001;90:4836-46.

[30] Ramesh Kumar P, Khan N, Vivekanandhan S, Satyanarayana N, Mohanty A, Misra M. Nanofibers: effective generation by electrospinning and their applications. J Nanosci Nanotechnol 2012;12:1-25.

[31] Jaworek A, Krupa A, Lackowski M, Sobczyk A, Czech T, Ramakrishna S, Pliszka D. Nanocomposite fabric formation by electrospinning and electrospraying technologies. $\mathrm{J}$ Electrostat 2009;67:435-8.

[32] Deitzel J, Kleinmeyer J, Harris Dea, Beck Tan N. The effect of processing variables on the morphology of electrospun nanofibers and textiles. Polymer 2001;42:261-72.

[33] Li WJ, Laurencin CT, Caterson EJ, Tuan RS, Ko FK. Electrospun nanofibrous structure: a novel scaffold for tissue engineering. J Biomed Mater Res 2002;60:613-21.

[34] Merrell JG, McLaughlin SW, Tie L, Laurencin CT, Chen AF, Nair LS. Curcumin-loaded poly(epsilon-caprolactone) nanofibres: diabetic wound dressing with anti-oxidant and anti-inflammatory properties. Clin Exp Pharmacol Physiol 2009;36:1149-56.

[35] Katti DS, Robinson KW, Ko FK, Laurencin CT. Bioresorbable nanofiber-based systems for wound healing and drug delivery: optimization of fabrication parameters. J Biomed Mater Res Part B 2004;70:286-96.

[36] Kumbar S, James R, Nukavarapu S, Laurencin C. Electrospun nanofiber scaffolds: engineering soft tissues. Biomed Mater 2008;3:034002/1-15.

[37] Kumbar SG, Nukavarapu SP, James R, Nair LS, Laurencin CT. Electrospun poly(lactic acid-co-glycolic acid) scaffolds for skin tissue engineering. Biomaterials 2008;29:4100-7. 
[38] Taylor ED, Nair LS, Nukavarapu SP, McLaughlin S, Laurencin CT. Novel nanostructured scaffolds as therapeutic replacement options for rotator cuff disease. $\mathrm{J}$ Bone Joint Surg 2010;92:170-9.

[39] James R, Kumbar S, Laurencin C, Balian G, Chhabra A. Tendon tissue engineering: adipose-derived stem cell and GDF-5 mediated regeneration using electrospun matrix systems. Biomed Mater 2011;6:025011/1-26.

[40] James R, Toti U, Laurencin C, Kumbar S. Electrospun nanofibrous scaffolds for engineering soft connective tissues. Methods Mol Biol 2010;726:243-58.

[41] Peach MS, James R, Toti US, Deng M, Morozowich NL, Allcock HR, Laurencin CT, Kumbar SG. Polyphosphazene functionalized polyester fiber matrices for tendon tissue engineering: in vitro evaluation with human mesenchymal stem cells. Biomed Mater 2012;7:045016/1-13.

[42] Peach MS, Kumbar SG, James R, Toti US, Balasubramaniam D, Deng M, Ulery B, Mazzocca AD, McCarthy MB, Morozowich NL, Alcock HR, Laurencin CT. Design and optimization of polyphosphazene functionalized fiber matrices for soft tissue regeneration. J Biomed Nanotechnol 2012;8:107-24.

[43] Wang J, Valmikinathan CM, Liu W, Laurencin CT, Yu X. Spiral-structured, nanofibrous, 3D scaffolds for bone tissue engineering. J Biomed Mater Res Part A 2010;93:753-62.

[44] Bhattacharyya S, Kumbar SG, Khan YM, Nair LS, Singh A, Krogman NR, Brown PW, Alcock HR, Laurencin CT. Biodegradable polyphosphazene-nanohydroxyapatite composite nanofibers: scaffolds for bone tissue engineering. J Biomed Nanotechnol 2009;5:69-75.

[45] Deng M, Kumbar SG, Nair LS, Weikel AL, Allcock HR, Laurencin CT. Biomimetic Structures: Biological Implications of Dipeptide-Substituted Polyphosphazene-Polyester Blend Nanofiber Matrices for Load-Bearing Bone Regeneration. Adv Funct Mater 2011;21:2641-51.

[46] Brown JL, Peach MS, Nair LS, Kumbar SG, Laurencin CT. Composite scaffolds: bridging nanofiber and microsphere architectures to improve bioactivity of mechanically competent constructs. J Biomed Mater Res Part A 2010;95:1150-8. 
[47] Huang Z-M, Zhang Y-Z, Kotaki M, Ramakrishna S. A review on polymer nanofibers by electrospinning and their applications in nanocomposites. Compos Sci Technol 2003;63:2223-53.

[48] Zhang Y, Venugopal JR, El-Turki A, Ramakrishna S, Su B, Lim CT. Electrospun biomimetic nanocomposite nanofibers of hydroxyapatite/chitosan for bone tissue engineering. Biomaterials 2008;29:4314-22.

[49] Bhattarai N, Edmondson D, Veiseh O, Matsen FA, Zhang M. Electrospun chitosan-based nanofibers and their cellular compatibility. Biomaterials 2005;26:6176-84.

[50] Geng X, Kwon O-H, Jang J. Electrospinning of chitosan dissolved in concentrated acetic acid solution. Biomaterials 2005;26:5427-32.

[51] Jiang T, Deng M, James R, Nair LS, Laurencin CT. Micro-and nanofabrication of chitosan structures for regenerative engineering. Acta Biomater 2013.;10:1632-45.

[52] Li M, Guo Y, Wei Y, MacDiarmid AG, Lelkes PI. Electrospinning polyaniline-contained gelatin nanofibers for tissue engineering applications. Biomaterials 2006;27:2705-15.

[53] Kim HW, Song JH, Kim HE. Nanofiber generation of gelatin-hydroxyapatite biomimetics for guided tissue regeneration. Adv Funct Mater 2005;15:1988-94.

[54] Yoshimoto H, Shin Y, Terai H, Vacanti J. A biodegradable nanofiber scaffold by electrospinning and its potential for bone tissue engineering. Biomaterials 2003;24:207782.

[55] Shin M, Yoshimoto H, Vacanti JP. In vivo bone tissue engineering using mesenchymal stem cells on a novel electrospun nanofibrous scaffold. Tissue Eng 2004;10:33-41.

[56] Yang F, Murugan R, Wang S, Ramakrishna S. Electrospinning of nano/micro scale poly(L-lactic acid) aligned fibers and their potential in neural tissue engineering. Biomaterials 2005;26:2603-10.

[57] Chen J, Chu B, Hsiao BS. Mineralization of hydroxyapatite in electrospun nanofibrous poly(L-lactic acid) scaffolds. J Biomed Mater Res Part A 2006;79:307-17.

[58] Xu C, Inai R, Kotaki M, Ramakrishna S. Aligned biodegradable nanofibrous structure: a potential scaffold for blood vessel engineering. Biomaterials 2004;25:877-86.

[59] Mo X, Xu C, Kotaki Mea, Ramakrishna S. Electrospun P(LLA-CL) nanofiber: a biomimetic extracellular matrix for smooth muscle cell and endothelial cell proliferation. Biomaterials 2004;25:1883-90. 
[60] Lee CH, Shin HJ, Cho IH, Kang Y-M, Kim I, Park K-D, Shin J-W. Nanofiber alignment and direction of mechanical strain affect the ECM production of human ACL fibroblast. Biomaterials 2005;26:1261-70.

[61] Khil MS, Cha DI, Kim HY, Kim IS, Bhattarai N. Electrospun nanofibrous polyurethane membrane as wound dressing. J Biomed Mater Res Part B 2003;67:675-9.

[62] Ghasemi-Mobarakeh L, Prabhakaran MP, Morshed M, Nasr-Esfahani M-H, Ramakrishna S. Electrospun poly( $\varepsilon$-caprolactone)/gelatin nanofibrous scaffolds for nerve tissue engineering. Biomaterials 2008;29:4532-9.

[63] Mohammadi Y, Soleimani M, Fallahi-Sichani M, Gazme A, Haddadi-Asl V, Arefian E, Kiani J, Moradi R, Atashi A, Ahmadbeigi N. Nanofibrous poly( $\varepsilon$ caprolactone)/poly(vinyl (alcohol)/chitosan hybrid scaffolds for bone tissue engineering using mesenchymal stem cells. Int J Artif Organs 2007;30:204-11.

[64] Dhandayuthapani B, Krishnan UM, Sethuraman S. Fabrication and characterization of chitosan-gelatin blend nanofibers for skin tissue engineering. J Biomed Mater Res Part B 2010;94:264-72.

[65] Kai D, Prabhakaran MP, Jin G, Ramakrishna S. Guided orientation of cardiomyocytes on electrospun aligned nanofibers for cardiac tissue engineering. J Biomed Mater Res Part B 2011;98:379-86.

[66] Kim HW, Yu HS, Lee HH. Nanofibrous matrices of poly(lactic acid) and gelatin polymeric blends for the improvement of cellular responses. J Biomed Mater Res Part A 2008;87:25-32.

[67] Christopherson GT, Song H, Mao HQ. The influence of fiber diameter of electrospun substrates on neural stem cell differentiation and proliferation. Biomaterials 2009;30:55664.

[68] Venugopal J, Ma L, Yong T, Ramakrishna S. In vitro study of smooth muscle cells on polycaprolactone and collagen nanofibrous matrices. Cell Biol Int 2005;29:861-7.

[69] Wang HB, Mullins ME, Cregg JM, Hurtado A, Oudega M, Trombley MT, Gilbert RJ. Creation of highly aligned electrospun poly-L-lactic acid fibers for nerve regeneration applications. J Neural Eng 2009;6:016001/1-15.

[70] Wang C-Y, Zhang K-H, Fan C-Y, Mo X-M, Ruan HJ, Li FF. Aligned natural-synthetic polyblend nanofibers for peripheral nerve regeneration. Acta Biomater 2011;7:634-43. 
[71] Jiang T, Abdel-Fattah WI, Laurencin CT. In vitro evaluation of chitosan/poly(lactic acidglycolic acid) sintered microsphere scaffolds for bone tissue engineering. Biomaterials 2006;27:4894-903.

[72] Jiang T, Khan Y, Nair LS, Abdel-Fattah WI, Laurencin CT. Functionalization of chitosan/poly(lactic acid-glycolic acid) sintered microsphere scaffolds via surface heparinization for bone tissue engineering. J Biomed Mater Res Part A 2010;93:1193-208.

[73] Lowery JL, Datta N, Rutledge GC. Effect of fiber diameter, pore size and seeding method on growth of human dermal fibroblasts in electrospun poly( $\varepsilon$-caprolactone) fibrous mats. Biomaterials 2010;31:491-504.

[74] Min B-M, Lee G, Kim SH, Nam YS, Lee TS, Park WH. Electrospinning of silk fibroin nanofibers and its effect on the adhesion and spreading of normal human keratinocytes and fibroblasts in vitro. Biomaterials 2004;25:1289-97.

[75] Ziabari M, Mottaghitalab V, Haghi AK. Evaluation of electrospun nanofiber pore structure parameters. Kor J Chem Eng 2008;25:923-32.

[76] Jena A, Gupta K. Pore volume of nanofiber nonwovens. Int Nonwovens J 2005;14:25-30.

[77] Frey MW, Li L. Electrospinning and porosity measurements of nylon-6/poly(ethylene oxide) blended non-wovens. J Eng Fibers Fabrics 2007;2:31-7.

[78] Gupta D, Venugopal J, Prabhakaran MP, Dev V, Low S, Choon AT, Ramakrishna S. Aligned and random nanofibrous substrate for the in vitro culture of Schwann cells for neural tissue engineering. Acta Biomater 2009;5:2560-9.

[79] Li D, Frey MW, Joo YL. Characterization of nanofibrous membranes with capillary flow porometry. J Memb Sci 2006;286:104-14.

[80] Soliman S, Pagliari S, Rinaldi A, Forte G, Fiaccavento R, Pagliari F, Franzese O, Minieri M, Di Nardo P, Licoccia S, Traversa E. Multiscale three-dimensional scaffolds for soft tissue engineering via multimodal electrospinning. Acta Biomater 2010;6:1227-37.

[81] Vasita R, Katti DS. Nanofibers and their applications in tissue engineering. Int J Nanomedicine 2006;1:15-30.

[82] Ma Z, Kotaki M, Inai R, Ramakrishna S. Potential of nanofiber matrix as tissueengineering scaffolds. Tissue Eng 2005;11:101-9.

[83] Langer R, Tirrell DA. Designing materials for biology and medicine. Nature 2004;428:487-92. 
[84] Langer R, Peppas NA. Advances in biomaterials, drug delivery, and bionanotechnology. AIChE J 2004;49:2990-3006.

[85] Rice JJ, Martino MM, De Laporte L, Tortelli F, Briquez PS, Hubbell JA. Engineering the Regenerative Microenvironment with Biomaterials. Adv Healthc Mater 2012.; 2:57-71.

[86] Matthews JA, Wnek GE, Simpson DG, Bowlin GL. Electrospinning of collagen nanofibers. Biomacromolecules 2002;3:232-8.

[87] Choi JS, Lee SJ, Christ GJ, Atala A, Yoo JJ. The influence of electrospun aligned poly( $(\varepsilon-$ caprolactone)/collagen nanofiber meshes on the formation of self-aligned skeletal muscle myotubes. Biomaterials 2008;29:2899-906.

[88] Katta P, Alessandro M, Ramsier R, Chase G. Continuous electrospinning of aligned polymer nanofibers onto a wire drum collector. Nano Lett 2004;4:2215-8.

[89] Theron A, Zussman E, Yarin A. Electrostatic field-assisted alignment of electrospun nanofibres. Nanotechnology 2001;12:384-90.

[90] Li D, Wang Y, Xia Y. Electrospinning of polymeric and ceramic nanofibers as uniaxially aligned arrays. Nano Lett 2003;3:1167-71.

[91] Xie J, MacEwan MR, Ray WZ, Liu W, Siewe DY, Xia Y. Radially aligned, electrospun nanofibers as dural substitutes for wound closure and tissue regeneration applications. ACS Nano 2010;4:5027-36.

[92] Yang D, Lu B, Zhao Y, Jiang X. Fabrication of aligned fibrous arrays by magnetic electrospinning. Adv Mater 2007;19:3702-6.

[93] Li D, Wang Y, Xia Y. Electrospinning nanofibers as uniaxially aligned arrays and layer-by-layer stacked films. Adv Mater 2004;16:361-6.

[94] Wang Y, Shi H, Qiao J, Tian Y, Wu M, Zhang W, Lin Y, Niu Z, Huang Y. Electrospun tubular scaffold with circumferentially aligned nanofibers for regulating smooth muscle cell growth. ACS Appl Mater Interfaces 2014.;6:2958-62.

[95] Wu H, Fan J, Chu C-C, Wu J. Electrospinning of small diameter 3-D nanofibrous tubular scaffolds with controllable nanofiber orientations for vascular grafts. J Mater Sci Mater Med 2010;21:3207-15.

[96] George MC, Braun PV. Multicompartmental materials by electrohydrodynamic cojetting. Angew Chem Int Ed 2009;48:8606-9. 
[97] Yoshida M, Roh KH, Mandal S, Bhaskar S, Lim D, Nandivada H, Deng X, Lahann J. Structurally Controlled Bio-hybrid Materials Based on Unidirectional Association of Anisotropic Microparticles with Human Endothelial Cells. Adv Mater 2009;21:4920-5.

[98] Roh K-H, Martin DC, Lahann J. Biphasic Janus particles with nanoscale anisotropy. Nat Mater 2005;4:759-63.

[99] Bhaskar S, Hitt J, Chang SWL, Lahann J. Multicompartmental microcylinders. Angew Chem Int Ed 2009;48:4589-93.

[100] Bhaskar S, Lahann J. Microstructured materials based on multicompartmental fibers. J Am Chem Soc 2009;131:6650-1.

[101] Mandal S, Bhaskar S, Lahann J. Micropatterned fiber scaffolds for spatially controlled cell adhesion. Macromol Rapid Commun 2009;30:1638-44.

[102] Jiang Y-N, Mo H-Y, Yu D-G. Electrospun drug-loaded core-sheath PVP/zein nanofibers for biphasic drug release. Int J Pharm 2012;438:232-9.

[103] Liao I, Chew S, Leong K. Aligned core-shell nanofibers delivering bioactive proteins. Nanomedicine 2006;1:465-71.

[104] Liao I, Chen S, Liu JB, Leong KW. Sustained viral gene delivery through core-shell fibers. J Controlled Release 2009;139:48-55.

[105] Yan S, Xiaoqiang L, Lianjiang T, Chen H, Xiumei M. Poly(l-lactide-co- $\varepsilon$-caprolactone) electrospun nanofibers for encapsulating and sustained releasing proteins. Polymer 2009;50:4212-9.

[106] Xu X, Zhuang X, Chen X, Wang X, Yang L, Jing X. Preparation of Core-Sheath Composite Nanofibers by Emulsion Electrospinning. Macromol Rapid Commun 2006;27:1637-42.

[107] Yu D-G, Chian W, Wang X, Li X-Y, Li Y, Liao Y-Z. Linear drug release membrane prepared by a modified coaxial electrospinning process. J Memb Sci 2013;428:150-6.

[108] Yang Y, Xia T, Zhi W, Wei L, Weng J, Zhang C, Li X. Promotion of skin regeneration in diabetic rats by electrospun core-sheath fibers loaded with basic fibroblast growth factor. Biomaterials 2011;32:4243-54. 
[109] Jo E, Lee S, Kim KT, Won YS, Kim HS, Cho EC, Jeong U. Core-Sheath Nanofibers Containing Colloidal Arrays in the Core for Programmable Multi-Agent Delivery. Adv Mater 2009;21:968-72.

[110] Wang Y, Qiao W, Yin T. A novel controlled release drug delivery system for multiple drugs based on electrospun nanofibers containing nanoparticles. J Pharm Sci 2010;99:4805-11.

[111] Lee KJ, Park T-H, Hwang S, Yoon J, Lahann J. Janus-core and shell microfibers. Langmuir 2013;29:6181-6.

[112] Liu A, Niswander LA. Bone morphogenetic protein signalling and vertebrate nervous system development. Nat Rev Neurosci 2005;6:945-54.

[113] Adams RH, Alitalo K. Molecular regulation of angiogenesis and lymphangiogenesis. Nat Rev Mol Cell Biol 2007;8:464-78.

[114] Liu W, Lipner J, Xie J, Manning CN, Thomopoulos S, Xia Y. Nanofiber Scaffolds with Gradients in Mineral Content for Spatial Control of Osteogenesis. ACS Appl Mater Interfaces 2014.;6:2842-9.

[115] Shi J, Wang L, Zhang F, Li H, Lei L, Liu L, Chen Y. Incorporating protein gradient into electrospun nanofibers as scaffolds for tissue engineering. ACS Appl Mater Interfaces 2010;2:1025-30.

[116] Du F, Wang H, Zhao W, Li D, Kong D, Yang J, Zhang Y. Gradient nanofibrous chitosan/poly $\varepsilon$-caprolactone scaffolds as extracellular microenvironments for vascular tissue engineering. Biomaterials 2012;33:762-70.

[117] Bottino MC, Thomas V, Janowski GM. A novel spatially designed and functionally graded electrospun membrane for periodontal regeneration. Acta Biomater 2011;7:21624.

[118] Pham QP, Sharma U, Mikos AG. Electrospun poly(e-caprolactone) microfiber and multilayer nanofiber/microfiber scaffolds: characterization of scaffolds and measurement of cellular infiltration. Biomacromolecules 2006;7:2796-805.

[119] Xie J, Li X, Lipner J, Manning CN, Schwartz AG, Thomopoulos S, Xia Y. “Aligned-torandom" nanofiber scaffolds for mimicking the structure of the tendon-to-bone insertion site. Nanoscale 2010;2:923-6. 
[120] Xie J, MacEwan MR, Li X, Sakiyama-Elbert SE, Xia Y. Neurite outgrowth on nanofiber scaffolds with different orders, structures, and surface properties. ACS Nano 2009;3:1151-9.

[121] Chen M, Patra PK, Warner SB, Bhowmick S. Role of fiber diameter in adhesion and proliferation of NIH $3 \mathrm{~T} 3$ fibroblast on electrospun polycaprolactone scaffolds. Tissue Eng 2007;13:579-87.

[122] Sisson K, Zhang C, Farach-Carson MC, Chase DB, Rabolt JF. Fiber diameters control osteoblastic cell migration and differentiation in electrospun gelatin. J Biomed Mater Res Part A 2010;94:1312-20.

[123] Baker BM, Gee AO, Metter RB, Nathan AS, Marklein RA, Burdick JA, Mauck RL. The potential to improve cell infiltration in composite fiber-aligned electrospun scaffolds by the selective removal of sacrificial fibers. Biomaterials 2008;29:2348-58.

[124] Phipps MC, Clem WC, Grunda JM, Clines GA, Bellis SL. Increasing the pore sizes of bone-mimetic electrospun scaffolds comprised of polycaprolactone, collagen I and hydroxyapatite to enhance cell infiltration. Biomaterials 2012;33:524-34.

[125] Lee YH, Lee JH, An I-G, Kim C, Lee DS, Lee YK, Nam J-D. Electrospun dual-porosity structure and biodegradation morphology of Montmorillonite reinforced PLLA nanocomposite scaffolds. Biomaterials 2005;26:3165-72.

[126] Blakeney BA, Tambralli A, Anderson JM, Andukuri A, Lim D-J, Dean DR, Jun H-W. Cell infiltration and growth in a low density, uncompressed three-dimensional electrospun nanofibrous scaffold. Biomaterials 2011;32:1583-90.

[127] Rnjak-Kovacina J, Wise SG, Li Z, Maitz PK, Young CJ, Wang Y, Weiss AS. Tailoring the porosity and pore size of electrospun synthetic human elastin scaffolds for dermal tissue engineering. Biomaterials 2011;32:6729-36.

[128] Balguid A, Mol A, van Marion MH, Bank RA, Bouten CV, Baaijens FP. Tailoring fiber diameter in electrospun poly( $\varepsilon$-caprolactone) scaffolds for optimal cellular infiltration in cardiovascular tissue engineering. Tissue Eng Part A 2008;15:437-44.

[129] Eichhorn SJ, Sampson WW. Statistical geometry of pores and statistics of porous nanofibrous assemblies. J Royal Soc Interface 2005;2:309-18.

[130] Ross MH, Kaye GI, Pawlina W. Histology: A Text and Atlas. Philadelphia PA: Lippincott Williams \& Wilkins, 2003. p. 201-37. 
[131] Bilezikian JP, Raisz LG, Rodan GA. Principles of bone biology. San Diego CA: Academic Press, 1996. p. 3-14.

[132] Li W-J, Mauck RL, Cooper JA, Yuan X, Tuan RS. Engineering controllable anisotropy in electrospun biodegradable nanofibrous scaffolds for musculoskeletal tissue engineering. $J$ Biomechanics 2007;40:1686-93.

[133] Meng Z, Wang Y, Ma C, Zheng W, Li L, Zheng Y. Electrospinning of PLGA/gelatin randomly-oriented and aligned nanofibers as potential scaffold in tissue engineering. Mater Sci Eng C 2010;30:1204-10.

[134] Yang S, Leong K-F, Du Z, Chua C-K. The design of scaffolds for use in tissue engineering. Part I. Traditional factors. Tissue Eng 2001;7:679-89.

[135] Whang K, Healy K, Elenz D, Nam E, Tsai D, Thomas C, Nuber GW, Glorieux FH, Travers R, Sprague SM. Engineering bone regeneration with bioabsorbable scaffolds with novel microarchitecture. Tissue Eng 1999;5:35-51.

[136] Badami AS, Kreke MR, Thompson MS, Riffle JS, Goldstein AS. Effect of fiber diameter on spreading, proliferation, and differentiation of osteoblastic cells on electrospun poly(lactic acid) substrates. Biomaterials 2006;27:596-606.

[137] Pelled G, Tai K, Sheyn D, Zilberman Y, Kumbar S, Nair LS, Laurencin CT, Gazit D, Ortiz C. Structural and nanoindentation studies of stem cell-based tissue-engineered bone. J Biomech 2007;40:399-411.

[138] Teshima R, Otsuka T, Takasu N, Yamagata N, Yamamoto K. Structure of the most superficial layer of articular cartilage. J Bone Joint Surg Br 1995;77:460-4.

[139] Ap Gwynn I, Wade S, Ito K, Richards R. Novel aspects to the structure of rabbit articular cartilage. Eur Cell Mater 2002;4:18-29.

[140] Subramanian A, Vu D, Larsen GF, Lin H-Y. Preparation and evaluation of the electrospun chitosan/PEO fibers for potential applications in cartilage tissue engineering. J Biomater Sci Polym Ed 2005;16:861-73.

[141] Shin HJ, Lee CH, Cho IH, Kim Y-J, Lee Y-J, Kim IA, Park KD, Yui N, Shin JW. Electrospun PLGA nanofiber scaffolds for articular cartilage reconstruction: mechanical stability, degradation and cellular responses under mechanical stimulation in vitro. $\mathrm{J}$ Biomater Sci Polym Ed 2006;17:103-19. 
[142] Alves da Silva M, Martins A, Costa-Pinto A, Costa P, Faria S, Gomes M, Reis RL, Neves NM. Cartilage tissue engineering using electrospun PCL nanofiber meshes and MSCs. Biomacromolecules 2010;11:3228-36.

[143] Wise JK, Yarin AL, Megaridis CM, Cho M. Chondrogenic differentiation of human mesenchymal stem cells on oriented nanofibrous scaffolds: engineering the superficial zone of articular cartilage. Tissue Eng Part A 2008;15:913-21.

[144] Baker BM, Nathan AS, Gee AO, Mauck RL. The influence of an aligned nanofibrous topography on human mesenchymal stem cell fibrochondrogenesis. Biomaterials 2010;31:6190-200.

[145] Wimpenny I, Ashammakhi N, Yang Y. Chondrogenic potential of electrospun nanofibres for cartilage tissue engineering. J Tissue Eng Regen Med 2012;6:536-49.

[146] Järvinen TA, Kannus P, Paavola M, Järvinen TL, Józsa L, Järvinen M. Achilles tendon injuries. Curr Opin Rheumatol 2001;13:150-5.

[147] Petrigliano FA, McAllister DR, Wu BM. Tissue engineering for anterior cruciate ligament reconstruction: a review of current strategies. Arthroscopy 2006;22:441-51.

[148] Jiang T, Deng M, Abdel-Fattah WI, Laurencin CT. Chitosan-based biopharmaceutical scaffolds in tissue engineering and regenerative medicine. In: Sarmento B, Das Neves J, editors. Chitosan-Based Systems For Biopharmaceuticals: Delivery, Targeting And Polymer Therapeutics. West Sussex, John Wiley \& Sons Inc, 2012. p. 393-427.

[149] Bashur CA, Shaffer RD, Dahlgren LA, Guelcher SA, Goldstein AS. Effect of fiber diameter and alignment of electrospun polyurethane meshes on mesenchymal progenitor cells. Tissue Eng Part A 2009;15:2435-45.

[150] Yin Z, Chen X, Chen JL, Shen WL, Hieu Nguyen TM, Gao L, Ouyang HW. The regulation of tendon stem cell differentiation by the alignment of nanofibers. Biomaterials 2010;31:2163-75.

[151] Doschak M, Zernicke R. Structure, function and adaptation of bone-tendon and boneligament complexes. J Musculoskelet Neuronal Interact 2005;5:35-40.

[152] Yang PJ, Temenoff JS. Engineering orthopedic tissue interfaces. Tissue Eng Part B 2009;15:127-41. 
[153] Li X, Xie J, Lipner J, Yuan X, Thomopoulos S, Xia Y. Nanofiber scaffolds with gradations in mineral content for mimicking the tendon-to-bone insertion site. Nano Lett 2009;9:2763-8.

[154] Samavedi S, Olsen Horton C, Guelcher SA, Goldstein AS, Whittington AR. Fabrication of a model continuously graded co-electrospun mesh for regeneration of the ligamentbone interface. Acta Biomater 2011;7:4131-8.

[155] Mackinnon SE, Hudson AR. Clinical application of peripheral nerve transplantation. Plast Reconstr Surg 1992;90:695-9.

[156] Subramanian A, Krishnan UM, Sethuraman S. Development of biomaterial scaffold for nerve tissue engineering: Biomaterial mediated neural regeneration. J Biomed Sci 2009; 16:108/1-11.

[157] Hadlock T, Sundback C, Hunter D, Cheney M, Vacanti JP. A polymer foam conduit seeded with Schwann cells promotes guided peripheral nerve regeneration. Tissue Eng 2000;6:119-27.

[158] Bini T, Gao S, Xu X, Wang S, Ramakrishna S, Leong K. Peripheral nerve regeneration by microbraided poly(L-lactide-co-glycolide) biodegradable polymer fibers. J Biomed Mater Res Part A 2004;68:286-95.

[159] Ono K, Kawamura K. Migration of immature neurons along tangentially oriented fibers in the subpial part of the fetal mouse medulla oblongata. Exp Brain Res 1989;78:290-300.

[160] Nadarajah B, Alifragis P, Wong RO, Parnavelas JG. Ventricle-directed migration in the developing cerebral cortex. Nat Neurosci 2002;5:218-24.

[161] O'Rourke NA, Sullivan DP, Kaznowski CE, Jacobs AA, McConnell SK. Tangential migration of neurons in the developing cerebral cortex. Development 1995;121:2165-76.

[162] Kim Y-t, Haftel VK, Kumar S, Bellamkonda RV. The role of aligned polymer fiberbased constructs in the bridging of long peripheral nerve gaps. Biomaterials 2008;29:3117-27.

[163] Schmidt CE, Leach JB. Neural tissue engineering: strategies for repair and regeneration. Annu Rev Biomed Eng 2003;5:293-347.

[164] Xie J, MacEwan MR, Schwartz AG, Xia Y. Electrospun nanofibers for neural tissue engineering. Nanoscale 2010;2:35-44. 
[165] Wang W, Itoh S, Konno K, Kikkawa T, Ichinose S, Sakai K, Ohkuma T, Watabe K. Effects of Schwann cell alignment along the oriented electrospun chitosan nanofibers on nerve regeneration. J Biomed Mater Res Part A 2009;91:994-1005.

[166] Wang W, Itoh S, Yamamoto N, Okawa A, Nagai A, Yamashita K. Enhancement of nerve regeneration along a chitosan nanofiber mesh tube on which electrically polarized $\beta$ tricalcium phosphate particles are immobilized. Acta Biomater 2010;6:4027-33.

[167] Koh H, Yong T, Teo W, Chan C, Puhaindran M, Tan T, Lim A, Lim B, Ramakrishna S. In vivo study of novel nanofibrous intra-luminal guidance channels to promote nerve regeneration. J Neural Eng 2010;7:046003/1-14.

[168] Wakelam M. The fusion of myoblasts. Biochem J 1985;228:1/1-12.

[169] Aviss K, Gough J, Downes S. Aligned electrospun polymer fibres for skeletal muscle regeneration. Eur Cell Mater 2010;19:193-204.

[170] Cooper A, Jana S, Bhattarai N, Zhang M. Aligned chitosan-based nanofibers for enhanced myogenesis. J Mater Chem 2010;20:8904-11.

[171] Shin S-H, Purevdorj O, Castano O, Planell JA, Kim H-W. A short review: Recent advances in electrospinning for bone tissue regeneration. J Tissue Eng 2012;3:2041731412443530 (11pp).

[172] Lyu S, Huang C, Yang H, Zhang X. Electrospun fibers as a scaffolding platform for bone tissue repair. J Orthop Res 2013;31:1382-9.

[173] Rim NG, Shin CS, Shin H. Current approaches to electrospun nanofibers for tissue engineering. Biomed Mater 2013;8:014102/1-14.

[174] Zhang Z, Hu J, Ma PX. Nanofiber-based delivery of bioactive agents and stem cells to bone sites. Adv Drug Deliv Rev 2012;64:1129-41.

[175] Schofer MD, Roessler PP, Schaefer J, Theisen C, Schlimme S, Heverhagen JT, Voelker M, Dersch R, Agarwal S, Fuchs-Winkelmann S, Paletta JR. Electrospun PLLA nanofiber scaffolds and their use in combination with BMP-2 for reconstruction of bone defects. Plos One 2011;6:e25462/1-9.

[176] Laurencin CT, Ashe KM, Henry N, Kan HM, Lo KW-H. Delivery of small molecules for bone regenerative engineering: preclinical studies and potential clinical applications. Drug Discov Today 2014.;19:794-800. 
[177] Wright L, McKeon-Fischer K, Cui Z, Nair L, Freeman J. PDLA/PLLA and PDLA/PCL nanofibers with a chitosan-based hydrogel in composite scaffolds for tissue engineered cartilage. J Tissue Eng Regen Med 2012.;DOI:10.1002/term.1591 (9pp).

[178] Son YJ, Kim WJ, Yoo HS. Therapeutic applications of electrospun nanofibers for drug delivery systems. Arch Pharm Res 2014;37:69-78.

[179] Chatakun P, Núñez-Toldrà R, López ED, Gil-Recio C, Martínez-Sarrà E, HernándezAlfaro F, Ferrés-Padró E, Giner-Tarrida L, Atari M. The effect of five proteins on stem cells used for osteoblast differentiation and proliferation: a current review of the literature. Cell Mol Life Sci 2014;71:113-42.

[180] Lieberman JR, Daluiski A, Einhorn TA. The role of growth factors in the repair of bone biology and clinical applications. J Bone Joint Surg 2002;84:1032-44.

[181] Urist MR. Bone: formation by autoinduction. Science 1965;150:893-9.

[182] Bessa PC, Casal M, Reis R. Bone morphogenetic proteins in tissue engineering: the road from laboratory to clinic, part II (BMP delivery). J Tissue Eng Regen Med 2008;2:81-96.

[183] Lo KW-H, Ulery BD, Ashe KM, Laurencin CT. Studies of bone morphogenetic proteinbased surgical repair. Adv Drug Deliv Rev 2012;64:1277-91.

[184] Lo KW, Ashe KM, Kan HM, Laurencin CT. The role of small molecules in musculoskeletal regeneration. Regen Med 2012;7:535-49.

[185] Li C, Vepari C, Jin H-J, Kim HJ, Kaplan DL. Electrospun silk-BMP-2 scaffolds for bone tissue engineering. Biomaterials 2006;27:3115-24.

[186] Casper CL, Yamaguchi N, Kiick KL, Rabolt JF. Functionalizing electrospun fibers with biologically relevant macromolecules. Biomacromolecules 2005;6:1998-2007.

[187] Kuihua Z, Chunyang W, Cunyi F, Xiumei M. Aligned SF/P (LLA-CL)-blended nanofibers encapsulating nerve growth factor for peripheral nerve regeneration. J Biomed Mater Res Part A 2014;102:2680-91.

[188] Manning C, Schwartz A, Liu W, Xie J, Havlioglu N, Sakiyama-Elbert S, Silva MJ, Xia Y, Gelberman RH, Thomopoulos S. Controlled delivery of mesenchymal stem cells and growth factors using a nanofiber scaffold for tendon repair. Acta Biomater 2013;9:690514. 
[189] Xie Z, Paras CB, Weng H, Punnakitikashem P, Su L-C, Vu K, Tang L, Yang J, Nguyen KT. Dual growth factor releasing multi-functional nanofibers for wound healing. Acta Biomater 2013;9:9351-9.

[190] Ferrand A, Eap S, Richert L, Lemoine S, Kalaskar D, Demoustier-Champagne S, Atmani H, Mély Y, Fioretti F, Schlatter G, Kuhn L, Ladam G, Benkirane-Jessel N. Osteogenetic Properties of Electrospun Nanofibrous PCL Scaffolds Equipped With Chitosan-Based Nanoreservoirs of Growth Factors. Macromol Biosci 2014;14:45-55.

[191] Neal RA, Tholpady SS, Foley PL, Swami N, Ogle RC, Botchwey EA. Alignment and composition of laminin-polycaprolactone nanofiber blends enhance peripheral nerve regeneration. J Biomed Mater Res Part A 2012;100:406-23.

[192] Junka R, Valmikinathan CM, Kalyon DM, Yu X. Laminin Functionalized Biomimetic Nanofibers for Nerve Tissue Engineering. J Biomater Tissue Eng 2013;3:494-502.

[193] Liu JJ, Wang CY, Wang JG, Ruan HJ, Fan CY. Peripheral nerve regeneration using composite poly(lactic acid-caprolactone)/nerve growth factor conduits prepared by coaxial electrospinning. J Biomed Mater Res Part A 2011;96:13-20.

[194] Selcan Gungor-Ozkerim P, Balkan T, Kose GT, Sezai Sarac A, Kok FN. Incorporation of growth factor loaded microspheres into polymeric electrospun nanofibers for tissue engineering applications. J Biomed Mater Res Part A 2014;102:1897-908.

[195] WH Lo K, D Ulery B, Deng M, M Ashe K, T Laurencin C. Current patents on osteoinductive molecules for bone tissue engineering. Recent Pat Biomed Eng 2011;4:153-67.

[196] Laurencin CT, Lo K. Bone morphogenetic proteins for bone regeneration and their alternatives. Curr Pharm Des 2013;19:3353-3.

[197] Blaich G, Janssen B, Roth G, Salfeld J. Overview: differentiating issues in the development of macromolecules compared with small molecules. In: Gad SC, editor. Handbook Of Pharmaceutical Biotechnology. Hoboken NJ: John Wiley \& Sons Inc, 2007. p. 89-123.

[198] Reid RC, Yau M-K, Singh R, Hamidon JK, Reed AN, Chu P, Suen JY, Stoermer MJ, Blakeney JS, Lim J, Faber JM, Fairlie DP. Downsizing a human inflammatory protein to a small molecule with equal potency and functionality. Nat Commun 2013;4:2802/1-9. 
[199] Mieszawska AJ, Kaplan DL. Smart biomaterials-regulating cell behavior through signaling molecules. BMC Biol 2010;8:59/1-3.

[200] Siddappa R, Martens A, Doorn J, Leusink A, Olivo C, Licht R, van Rijn L, Gaspar C, Fodde R, Janssen F, van Blitterswijk C, de Boer J. cAMP/PKA pathway activation in human mesenchymal stem cells in vitro results in robust bone formation in vivo. Proc Nat Acad Sci USA 2008;105:7281-6.

[201] Siddappa R, Mulder W, Steeghs I, van de Klundert C, Fernandes H, Liu J, Arends R, van Blitterswijk C, de Boer J. cAMP/PKA signaling inhibits osteogenic differentiation and bone formation in rodent models. Tissue Eng Part A 2009;15:2135-43.

[202] Lo KWH, Kan HM, Ashe KM, Laurencin CT. The small molecule PKA-specific cyclic AMP analogue as an inducer of osteoblast-like cells differentiation and mineralization. $\mathrm{J}$ Tissue Eng Regen Med 2012;6:40-8.

[203] Lo KWH, Kan HM, Gagnon KA, Laurencin CT. One-day treatment of small molecule 8-bromo-cyclic AMP analogue induces cell-based VEGF production for in vitro angiogenesis and osteoblastic differentiation. J Tissue Eng Regen Med 2013.;DOI:10.1002/term.1839/1-9.

[204] Kouhi M, Morshed M, Varshosaz J, Fathi MH. Poly(e-caprolactone) incorporated bioactive glass nanoparticles and simvastatin nanocomposite nanofibers: Preparation, characterization and in vitro drug release for bone regeneration applications. Chem Eng J 2013;228:1057-65.

[205] Singh H, James E, Kan H-M, Nair LS. Fabrication and evaluation of resveratrol loaded polymeric nanofibers. J Biomater Tissue Eng 2012;2:228-35.

[206] Das A, Segar CE, Hughley BB, Bowers DT, Botchwey EA. The promotion of mandibular defect healing by the targeting of S1P receptors and the recruitment of alternatively activated macrophages. Biomaterials 2013;34:9853-62.

[207] Rishton GM. Small molecules that promote neurogenesis in vitro. Recent Pat CNS Drug Discov 2008;3:200-8.

[208] Teo W, Ramakrishna S. A review on electrospinning design and nanofibre assemblies. Nanotechnology 2006;17:R89-R106 
[209] Whited BM, Whitney JR, Hofmann MC, Xu Y, Rylander MN. Pre-osteoblast infiltration and differentiation in highly porous apatite-coated PLLA electrospun scaffolds. Biomaterials 2011;32:2294-304.

[210] Keun Kwon I, Kidoaki S, Matsuda T. Electrospun nano-to microfiber fabrics made of biodegradable copolyesters: structural characteristics, mechanical properties and cell adhesion potential. Biomaterials 2005;26:3929-39.

[211] Liu W, Yeh Y-C, Lipner J, Xie J, Sung H-W, Thomopoulos S, Xia Y. Enhancing the stiffness of electrospun nanofiber scaffolds with a controlled surface coating and mineralization. Langmuir 2011;27:9088-93.

[212] Zhou X, Cai Q, Yan N, Deng X, Yang X. In vitro hydrolytic and enzymatic degradation of nestlike-patterned electrospun poly(D, L-lactide-co-glycolide) scaffolds. J Biomed Mater Res Part A 2010;95:755-65. 
Figure 1. (A) Schematic diagram of the electrospinning process. (B) A stationary metal collector. (C) Randomly-oriented nanofibers collected on the stationary collector. (D) A rotating drum collector. (E) Uniaxially aligned nanofibers collected on the rotating drum collector.

Figure 2. Aligned nanofibers. (A) Uniaxially aligned nanofibers. (B) Radially aligned poly ( $\varepsilon-$ caprolactone) nanofibers on a ring collector. (C) Optical micrograph of a nanofibrous mesh formed by stacking two orthotropic layers of poly(vinyl pyrrolidone) nanofibers. (D) Camera images of the front view and cross section view of a poly ( $\varepsilon$-caprolactone) tubular scaffold made of both axial and circumferentially aligned nanofibers. The insets in (D) show the magnified area of the white boxes. Reproduced with permission from [90], Copyright 2003, [91], Copyright 2010, the American Chemical Society, and [95], Copyright 2010, Springer.

Figure 3. Biphasic Janus microfibers (A-D) fabricated by electrohydrodynamic co-spinning and coresheath nanofibers (E-F) fabricated by conventional electrospinning show two distinct fiber phases. (A) A confocal micrograph shows a bicompartmental Janus fiber structure. Only the red fluorescently labeled side of the Janus fiber contained acetylene groups, which were further modified with green fluorescently labeled peptide. (B) Both sides of the Janus fiber contained acetylene groups, which were modified with green fluorescently labeled peptide. Fibroblasts were shown to adhere only to the peptide modified fiber compartment in (C) and to both compartments of the peptide modified fibers in (D). (E) An SEM micrograph of a coresheath nanofibrous mesh consisting of a chitosan nanoparticle core and PCL sheath. A small molecule model drug, Rhodamine B, was encapsulated into the chitosan nanoparticles in the core. A second small molecule drug, Naproxen, was incorporated into the nanofiber sheath. White arrows indicate the locations of the chitosan nanoparticles. (F) A fluorescent image of fluorescein isothiocyanate (FITC)-conjugated chitosan nanoparticle/PCL core-sheath nanofibers. The green fluorescent dots are chitosan nanoparticles labeled with FITC. (G) An SEM micrograph shows the cross-section of a triphasic microfiber consisting of a biphasic Janus fiber core and PLGA shell. $(\mathrm{H})$ An overlay of confocal and differential interference contrast microscopy images of the fiber cross-section shows the two compartments of the Janus core, labeled with green and blue fluorescence, and the PLGA shell. The scale bar stands for $20 \mu \mathrm{m}$ in (A)-(D) and (H), $10 \mu \mathrm{m}$ in $(\mathrm{G})$, and $5 \mu \mathrm{m}$ in $(\mathrm{G})$ inset. Reproduced with permission from [101], Copyright 2009, [110], Copyright 2010 John Wiley \& Sons Inc, and [111], Copyright 2013, the American Chemical Society.

Figure 4. Nanofibrous scaffolds with gradients. (A) Experimental setup for fabricating PLGA nanofibrous scaffolds with a gradient in mineral content (left) and the scanning electron 
micrographs showing increasing calcium phosphate coating (right, from top to bottom). (B) A graded chitosan/PCL blend nanofibrous scaffold exhibiting chitosan-rich and PCL-rich portions (left: chitosan stained red, PCL stained green). Since heparin binds specifically to chitosan through ionic interaction and the growth factor VEGF binds to heparin, gradients in bioactive molecules heparin and VEGF can be established (schematic diagram on right). (C) Scanning electron micrographs of multilayered scaffolds with alternating layers of poly $(\varepsilon-$ caprolactone) nanofibers and microfibers. (D), (E), and (F) show the magnified images of the corresponding areas in (C). (G) Scanning electron micrograph of random-to-aligned nanofibrous mat. The Fourier Fast Transfer patterns in the inset indicate randomness and alignment of nanofibers on two sides. The scale bar stands for $100 \mu \mathrm{m}$ in (C) and $25 \mu \mathrm{m}$ in (D)(F). Reproduced with permission from [114], Copyright 2014, [118], Copyright 2006, [120], Copyright 2009, the American Chemical Society and [116], Copyright 2012, Elsevier Ltd,

Figure 5. Strategies to fabricate nanofibrous scaffolds with large pores. (A) A nanofibrous scaffold consisting of "PCL, collagen I, nanoparticulate hydroxyapatite" (stained green), and watersoluble PEO (stained red). (B) Removal of the sacrificial PEO nanofibers led to increase in pore sizes. (C) An electrospun PLLA composite scaffold containing salt particles. (D) A scanning electron micrograph of the scaffold in (C) after the salt leaching/gas forming process, showing the formation of micro-sized pores in the range of $50-300 \mu \mathrm{m}$. (E) A traditional electrospun PCL scaffold with a flat, two-dimensional structure. Inset: SEM of the flat PCL scaffold. (F) A cotton ball-like electrospun PCL scaffold showing a fluffy, three-dimensional structure. Inset: SEM of the cotton ball-like scaffold. Larger pores were observed in the fluffy, three-dimensional scaffold. (G) Electrospun gelatin nanofibrous mesh with nanofiber diameter of approximately $110 \mathrm{~nm}$. (H) Electrospun gelatin nanofibrous mesh with a wider nanofiber diameter of $600 \mathrm{~nm}$, leading to the formation of larger pores. Reproduced with permission from [124], Copyright 2012, Elsevier Ltd, [125], Copyright 2005, Elsevier Ltd, [126], Copyright 2011, Elsevier Ltd, and [122], Copyright 2010, John Wiley \& Sons Inc.

Figure 6. (A) Scanning electron micrograph showing the morphology of a 3D biomimetic nanofibrous scaffold seeded with primary rat osteoblasts and cultured for 28 days. (B) A representative plot of the stress-strain curve of the 3D biomimetic scaffold. The compressive modulus of the scaffold was in the mid-range of human trabecular bone. (C) ECM deposited by the cells bridging the gaps of concentric pattern by 28 days. (D) Immunohistochemical staining for osteopontin, a prominent component of the mineralized ECM, illustrating a homogenous ECM distribution throughout the scaffold after culturing for 28 days. Reproduced with permission from [45], Copyright 2011, John Wiley \& Sons Inc. 
Figure 7. Electrospun tubular chitosan nanofibrous scaffolds for nerve regeneration. (A) Non-oriented chitosan nanofiber mesh tube. (B) Oriented chitosan nanofiber mesh tube. (C) Bilayered chitosan nanofiber mesh tube with random fibers in the outer layer and aligned fibers in the inner layer. Insets in $(A)-(C)$ show the orientation of chitosan nanofibers for each tubular structure. (D) Histological image of the non-oriented group showing regenerated axons scattered in the loose connective tissue of the lumen, with some blood vessels of large diameters (V). (E) Many large diameter myelinated axons have matured to mass in the oriented group. (F) Histological image showing a high profile of middle-sized axons in the bilayered group. Scale bars in (D)-(F) stand for $20 \mu \mathrm{m}$. Reproduced with permission from [165], Copyright 2008, John Wiley \& Sons Inc.

Figure 8. Immunofluorescent staining images of human skeletal muscle cells on electrospun PCL/collagen nanofiber meshes. (A-C) randomly oriented and (E-G) aligned electrospun meshes; (A, E) desmin-positive expression at 3 days after cell seeding, (B, F) myosin heavy chain positive expression at 7 days after cell differentiation, and $(C, G)$ sarcomeric actinpositive expression at 7 days after cell differentiation. Laser confocal microscopy images of $\mathrm{F}$ actin staining on (D) randomly oriented and (H) aligned electrospun PCL/collagen nanofiber meshes. Reproduced with permission from [87], Copyright 2008, Elsevier Ltd.

Figure 9. Schematic representation showing the typical nanofiber-based growth factor delivery strategies: (A) physical adsorption; (B) coaxial electrospinning; (C) pore surface immobilization of growth factor-loaded particles; and (D) surface covalent immobilization of growth factors. Reproduced with permission from [174], Copyright 2012, Elsevier Ltd. 
Figure 1

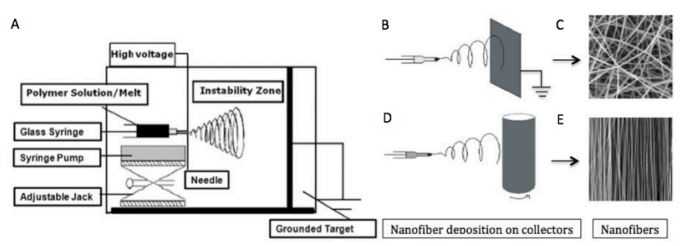

Figure 2

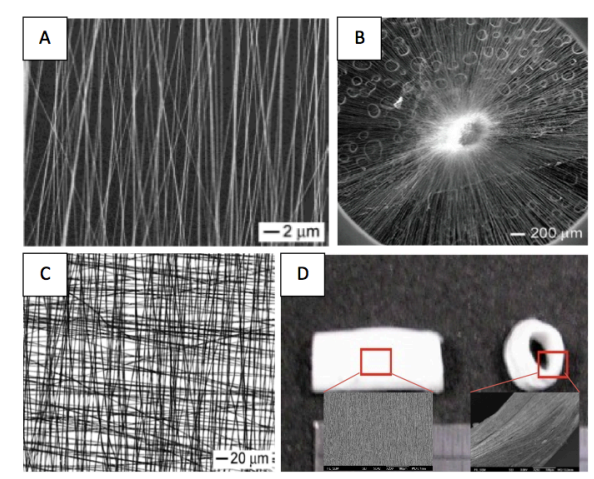

Figure 3

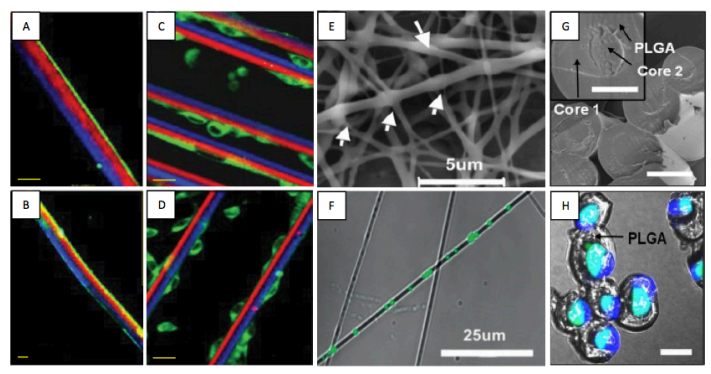


Figure 4

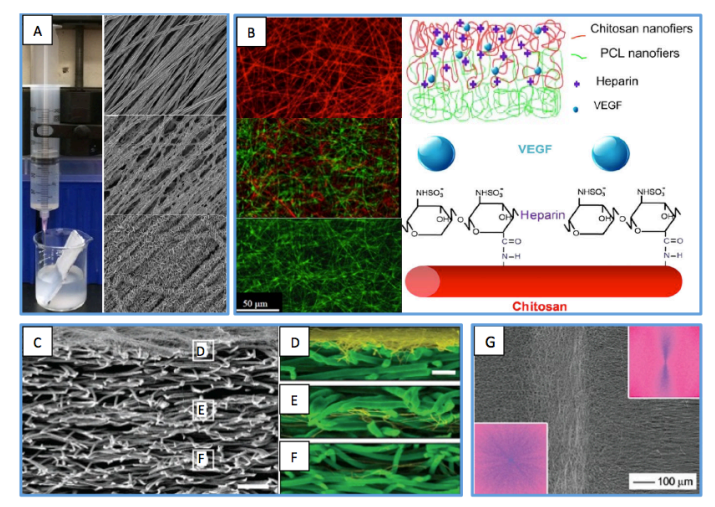

Figure 5

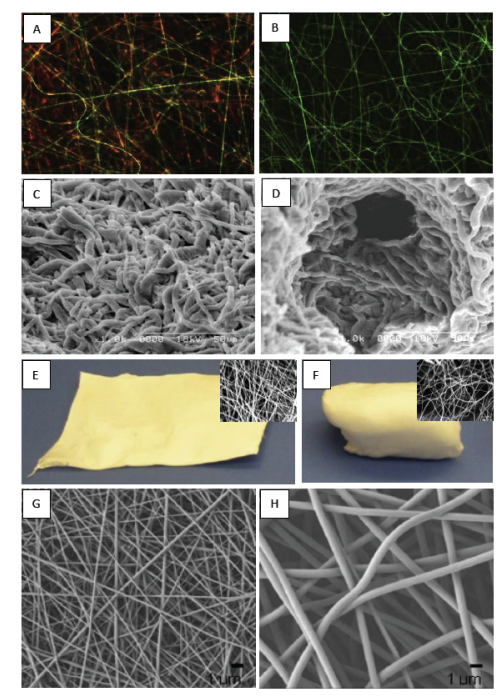


Figure 6

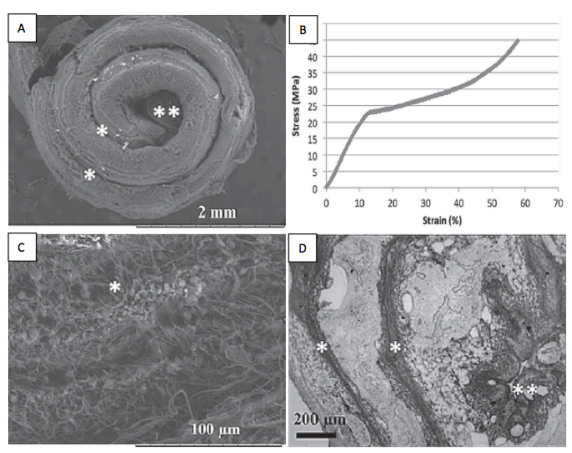

Figure 7

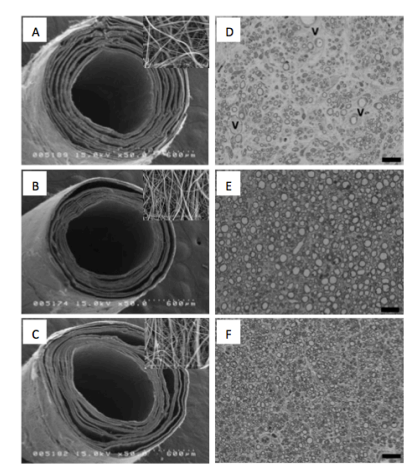


Figure 8

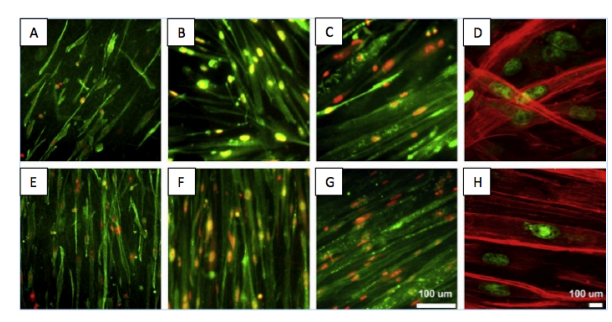

Figure 9

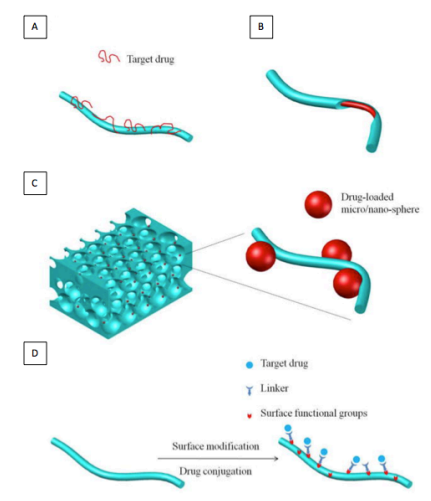


Table 1. Growth factor delivery for musculoskeletal tissue regeneration.

\begin{tabular}{|c|c|c|c|c|}
\hline $\begin{array}{l}\text { Growth } \\
\text { Factor }\end{array}$ & Nanofibrous Polymer & $\begin{array}{l}\text { Target Tissue } \\
\text { for Regeneration }\end{array}$ & Study Models & References \\
\hline BMP-2 & $\begin{array}{l}\text { Physical adsorption onto } \\
\text { PCL-based nanofiber }\end{array}$ & Bone & $\begin{array}{l}\text { In vitro: human } \\
\text { primary osteoblasts } \\
\text { In vivo: murine } \\
\text { calvarial bone defect } \\
\text { repair }\end{array}$ & {$[190]$} \\
\hline BMP-2 & PLLA-based nanofiber & Bone & $\begin{array}{l}\text { In vivo: rat critical } \\
\text { size calvarial defect } \\
\text { repair }\end{array}$ & {$[175]$} \\
\hline BMP-2 & $\begin{array}{l}\text { Silk fibroin/PEO-blended } \\
\text { nanofiber }\end{array}$ & Bone & $\begin{array}{l}\text { In vitro: human bone } \\
\text { marrow-derived } \\
\text { mesenchymal stem } \\
\text { cells }\end{array}$ & {$[185]$} \\
\hline bFGF & $\begin{array}{ll}\text { PEG-based nanofiber } \\
\text { with LMWH }\end{array}$ & $\begin{array}{l}\text { Musculoskeletal } \\
\text { tissue }\end{array}$ & Not reported & {$[186]$} \\
\hline Laminin & $\begin{array}{l}\text { Laminin-PCL blend } \\
\text { nanofibers }\end{array}$ & Peripheral nerve & $\begin{array}{l}\text { In vivo: rat tibial } \\
\text { nerve defect repair }\end{array}$ & [191] \\
\hline Laminin & PCL-chitosan nanofibers & Peripheral nerve & $\begin{array}{l}\text { In vitro: Schwann } \\
\text { cells }\end{array}$ & {$[192]$} \\
\hline NGF & $\begin{array}{l}\text { Silk fibroin/P(LLA-CL)- } \\
\text { blended nanofiber }\end{array}$ & Peripheral nerve & $\begin{array}{l}\text { In vitro: } \mathrm{PC} 12 \text { cells } \\
\text { In vivo: rat sciatic } \\
\text { nerve defect repair }\end{array}$ & {$[187]$} \\
\hline NGF & $\mathrm{P}(\mathrm{LLA}-\mathrm{CL})$ & Peripheral nerve & $\begin{array}{l}\text { In vivo: rat sciatic } \\
\text { nerve ligation model }\end{array}$ & [193] \\
\hline PDGF & $\begin{array}{l}\text { PDGF-loaded hydrogel } \\
\text { embedded in PLGA }\end{array}$ & Tendon & $\begin{array}{l}\text { In vivo: large animal } \\
\text { tendon model }\end{array}$ & {$[188]$} \\
\hline $\begin{array}{l}\text { PDGF + } \\
\text { VEGF }\end{array}$ & $\begin{array}{l}\text { PDGF-loaded PLGA- } \\
\text { based nanoparticles } \\
\text { embedded in VEGF- } \\
\text { loaded chitosan/PEO- } \\
\text { blended nanofiber }\end{array}$ & Skin & $\begin{array}{l}\text { In vitro: human } \\
\text { dermal fibroblasts } \\
\text { In vivo: rat full } \\
\text { thickness skin } \\
\text { wound repair }\end{array}$ & [189] \\
\hline FGF-2 & $\begin{array}{l}\text { FGF-2-loaded gelatin } \\
\text { microspheres } \\
\text { incorporated between } \\
\text { PCL/PLLA- and } \\
\text { PCL/gelatin-blended } \\
\text { nanofiber layers }\end{array}$ & $\begin{array}{l}\text { Bone, specifically } \\
\text { at } \\
\text { ligament/tendon/ } \\
\text { cartilage-to-bone } \\
\text { interfaces }\end{array}$ & $\begin{array}{l}\text { In vitro: human } \\
\text { osteoblasts }\end{array}$ & {$[194]$} \\
\hline
\end{tabular}

